\title{
Peptidases Prevent $\mu$-0pioid Receptor Internalization in Dorsal Horn Neurons by Endogenously Released Opioids
}

\author{
Bingbing Song and Juan Carlos G. Marvizón \\ Center for Neurovisceral Sciences and Women's Health, Division of Digestive Diseases, Department of Medicine, Geffen School of Medicine at University of \\ California Los Angeles, Los Angeles, California 90095
}

To evaluate the effect of peptidases on $\mu$-opioid receptor (MOR) activation by endogenous opioids, we measured MOR-1 internalization in rat spinal cord slices. A mixture of inhibitors of aminopeptidases (amastatin), dipeptidyl carboxypeptidase (captopril), and neutral endopeptidase (phosphoramidon) dramatically increased the potencies of Leu-enkephalin and dynorphin A to produce MOR-1 internalization, and also enhanced the effects of Met-enkephalin and $\alpha$-neoendorphin, but not endomorphins or $\beta$-endorphin. The omission of any one inhibitor abolished Leu-enkephalin-induced internalization, indicating that all three peptidases degraded enkephalins. Amastatin preserved dynorphin A-induced internalization, and phosphoramidon, but not captopril, increased this effect, indicating that the effect of dynorphin A was prevented by aminopeptidases and neutral endopeptidase. Veratridine $(30 \mu \mathrm{M})$ or $50 \mathrm{~mm} \mathrm{KCl}$ produced MOR-1 internalization in the presence of peptidase inhibitors, but little or no internalization in their absence. These effects were attributed to opioid release, because they were abolished by the selective MOR antagonist CTAP (D-Phe-Cys-Tyr-D-Trp-Arg-Thr-Pen-Thr$\mathrm{NH}_{2}$ ) and were $\mathrm{Ca}^{2+}$ dependent. The effect of veratridine was protected by phosphoramidon plus amastatin or captopril, but not by amastatin plus captopril or by phosphoramidon alone, indicating that released opioids are primarily cleaved by neutral endopeptidase, with a lesser involvement of aminopeptidases and dipeptidyl carboxypeptidase. Therefore, because the potencies of endomorphin-1 and endomorphin-2 to elicit internalization were unaffected by peptidase inhibitors, the opioids released by veratridine were not endomorphins. Confocal microscopy revealed that MOR-1-expressing neurons were in close proximity to terminals containing opioids with enkephalin-like sequences. These findings indicate that peptidases prevent the activation of extrasynaptic MOR-1 in dorsal horn neurons.

Key words: amastatin; aminopeptidase; captopril; dipeptidyl carboxypeptidase; dynorphin; endocytosis; endomorphin; endorphin; enkephalin; internalization; $\mu$-opioid receptor; neutral endopeptidase; opioid; peptidase; phosphoramidon; rat; release; spinal cord

\section{Introduction}

Pain neurophysiology was greatly advanced by the discovery of opioid receptors and endogenous opioids (for review, see Mansour et al., 1988; Law et al., 2000; Przewlocki and Przewlocka, 2001). These findings made it possible, in principle, to trace causal links between stimuli, opioid release, opioid receptor activation, and analgesic responses. However, measuring opioid release cannot predict opioid receptor activation, because it may be produced by peptides different from the one being detected, and it is impossible to know the peptide concentration at the receptor. These problems may be avoided by using opioid receptor internalization to assess their activation by a given stimulus, independently of the particular opioid being released. This approach was successfully used to study the activation of neurokinin 1 receptors by neurokinins released by noxious stimuli (Mantyh et al., 1995; Abbadie et al., 1997; Allen et al., 1997; Liu et al., 1997; Honore et al., 1999; Trafton et al., 1999, 2001) or after primary afferent stimulation (Marvizon et al., 1997, 1999a; Allen et al., 1999).

Received Sept. 25, 2002; revised Dec. 10, 2002; accepted Dec. 12, 2002.

This work was supported by National Institute on Drug Abuse Grant R01-DA12609 to J.C.M. We thank Drs. Chris Evans, Marzia Malcangio, and Emeran Mayer for critically reading this manuscript; Drs. Enrico Stefani, Catia Sternini, and Ligia Toro for their advice and support; Dr. Sherwin Wilk for providing alanine-pyrrolidonyl-2-nitrile; and Kendrick Che and Anish R. Dube for their help. We are also grateful for the assistance of Dr. Matthew J. Schibler at the University of California Los Angeles Carol Moss Spivak Cell Imaging Facility.

Correspondence should be addressed to Juan Carlos G. Marvizón, 1541 MacDonald Research Laboratories, 675 Charles E. Young Drive, University of California Los Angeles, Los Angeles, CA 90095. E-mail: marvizon@ucla.edu. Copyright $\odot 2003$ Society for Neuroscience $\quad 0270-6474 / 03 / 231847-12 \$ 15.00 / 0$
Conceivably, the internalization of $\mu$-opioid receptors (MORs) could be used similarly to detect their activation by endogenously released opioids.

In the dorsal horn, MOR-1 is present in dorsal horn interneurons (Kemp et al., 1996), whereas the splice variants MOR-1C and MOR-1D are found in primary afferent terminals (Abbadie et al., 2001), where they control substance P release (Yaksh et al., 1980; Aimone and Yaksh, 1989). MOR-1 in dorsal horn neurons readily internalized when exposed to etorphine or $\left[\mathrm{D}-\mathrm{Ala}^{2}, \mathrm{NMe}-\right.$ $\mathrm{Phe}^{4}, \mathrm{Gly}^{-\mathrm{ol}^{5}}$ ]-enkephalin (DAMGO), and the potency of DAMGO was similar to its potency to inhibit adenylyl cyclase (Marvizon et al., 1999b). Furthermore, MOR-1 internalization produced by intrathecal DAMGO correlated with its ability to elicit analgesia (Trafton et al., 2000). However, it remains to be established whether endogenous opioids, unlike morphine (Keith et al., 1998), produce MOR-1 internalization. If this were true, then MOR-1 internalization could be used as a marker of its activation by endogenous opioids. MOR-1 internalization attributable to opioid release was demonstrated in hypothalamic neurons after estrogen treatment (Eckersell et al., 1998) but has proved elusive in dorsal horn neurons. It was not elicited by primary afferent stimulation (Trafton et al., 1997) or, surprisingly, by noxious stimuli (Trafton et al., 2000) able to evoke the spinal release of Met-enkephalin (Le Bars et al., 1987a; Cesselin et al., 1989; Bourgoin et al., 1990). Furthermore, the ability of Metenkephalin to elicit MOR-1 internalization (Trafton et al., 2000) 
was much lower than its affinity for MOR-1 (Raynor et al., 1993; Zadina et al., 1997).

We hypothesized that MOR-1 internalization by endogenous opioids is prevented by their rapid degradation by peptidases. Indeed, enkephalins (Guyon et al., 1979; Chou et al., 1984; Yaksh and Chipkin, 1989; Hiranuma et al., 1997; Hiranuma et al., 1998a) and dynorphins (Hiranuma et al., 1998b) are quickly degraded in the intestine, brain, and spinal cord by three peptidases: neutral endopeptidase, dipeptidyl carboxypeptidase, and aminopeptidases (Fig. 1). We tested our hypothesis by investigating the ability of peptidase inhibitors to protect MOR-1 internalization produced by exogenously added and endogenously released opioids. These results have been published previously in abstract form (Song and Marvizon, 2002).

\section{Materials and Methods}

Chemicals. Ala-pyrrolidine-nitrile (Li et al., 1995) was a gift from Dr. Sherwin Wilk (Mount Sinai School of Medicine, New York, NY). $\alpha$-Neoendorphin and phosphoramidon were purchased from Bachem/ Peninsula Laboratories (San Carlos, CA). Other chemicals were obtained from Sigma (St. Louis, MO).

Media for slices. Artificial CSF (ACSF) contained (in mM): $124 \mathrm{NaCl}$, $1.9 \mathrm{KCl}, 26 \mathrm{NaHCO}_{3}, 1.2 \mathrm{KH}_{2} \mathrm{PO}_{4}, 1.3 \mathrm{MgSO}_{4}, 2.4 \mathrm{CaCl}_{2}$, and 10 glucose, and was $305 \mathrm{mOsm} . \mathrm{K}^{+}$-ACSF contained a higher concentration ( $5 \mathrm{~mm}$ ) of $\mathrm{KCl}$. Sucrose-ACSF was identical to ACSF, except that $\mathrm{NaCl}$ was isoosmotically replaced by sucrose $(215 \mathrm{~mm})$ and the concentration of $\mathrm{KCl}$ was $5 \mathrm{~mm}$. To depolarize the slices, we used ACSF ( $50 \mathrm{~mm} \mathrm{KCl}$ ) in which the concentration of $\mathrm{KCl}$ was increased to $50 \mathrm{~mm}$ and the concentration of $\mathrm{NaCl}$ was decreased to $74 \mathrm{~mm}$. All of these media were constantly bubbled with $95 \% \mathrm{O}_{2}$ and $5 \% \mathrm{CO}_{2}$ to a $\mathrm{pH}$ of 7.4 .

Spinal cord slice preparation. All animal procedures were approved by the Chancellor's Animal Research Committee at the University of California Los Angeles and conform to National Institutes of Health guidelines. Slices were prepared as described previously (Randic et al., 1993; Marvizon et al., 1997, 1999a,b; Sandkuhler et al., 1997). Briefly, 3- to 4-week-old Sprague Dawley rats (Harlan, Indianapolis, IN) were anesthetized with isoflurane (Halocarbon Laboratories, River Edge, NJ), and a laminectomy was performed to extract a lumbar segment of the spinal cord. The spinal cord was placed in ice-cold sucrose-ACSF in less than 1 min after the spine was pierced and cleaned of dura mater and roots. Coronal spinal cord slices $(400 \mu \mathrm{m})$ were cut with a Vibratome (Technical Products International, St. Louis, MO) in ice-cold sucrose-ACSF, using minimum forward speed and maximum vibration amplitude. Up to six slices were obtained from each animal, in the L1-L4 region. After cutting, slices were kept for $1 \mathrm{hr}$ in $\mathrm{K}^{+}-\mathrm{ACSF}$ at $35^{\circ} \mathrm{C}$ and then transferred to ACSF at $35^{\circ} \mathrm{C}$. It was vital that the slices contained healthy neurons, which required the use of a Vibratome and spinal cords rapidly extracted from live rats to make the slices.

Slice treatment. Slices were placed in a nylon net suspended halfway inside a small beaker and incubated at $35^{\circ} \mathrm{C}$ with ACSF containing various compounds, constantly bubbled with $95 \% \mathrm{O}_{2}$ and $5 \% \mathrm{CO}_{2}$. Peptidase inhibitors (usually amastatin, phosphoramidon, and captopril) were used at $10 \mu \mathrm{M}$, unless otherwise indicated. Phosphoramidon was always added together with $6 \mu \mathrm{M}$ dithiothreitol to protect it against oxidation. The incubation was ended by placing the slices in cold fixative.

MOR-1 immunohistochemistry in spinal cord slices. Histological sections from spinal cord slices were prepared and labeled as described previously (Marvizon et al., 1999b). Slices were fixed in 4\% paraformaldehyde, $0.2 \%$ picric acid, and $0.1 \mathrm{~m}$ sodium phosphate, $\mathrm{pH} 7.4$; cryoprotected in $20 \%$ sucrose; frozen on dry ice; and sectioned with a cryostat at $25 \mu \mathrm{m}$ in the coronal plane. Sections were washed twice with PBS; washed twice with PBS, $0.3 \%$ Triton X-100, and $0.001 \%$ thimerosal (PBS/Triton) containing 5\% normal goat serum; and then incubated at room temperature for $1 \mathrm{hr}$ and at $4^{\circ} \mathrm{C}$ overnight (12-18 hr) with the primary antibody diluted 1:7000 in PBS/Triton. The primary antibody was a rabbit antiserum raised against a synthetic peptide corresponding to amino acids $384-398$ of the cloned rat MOR-1 (catalog number

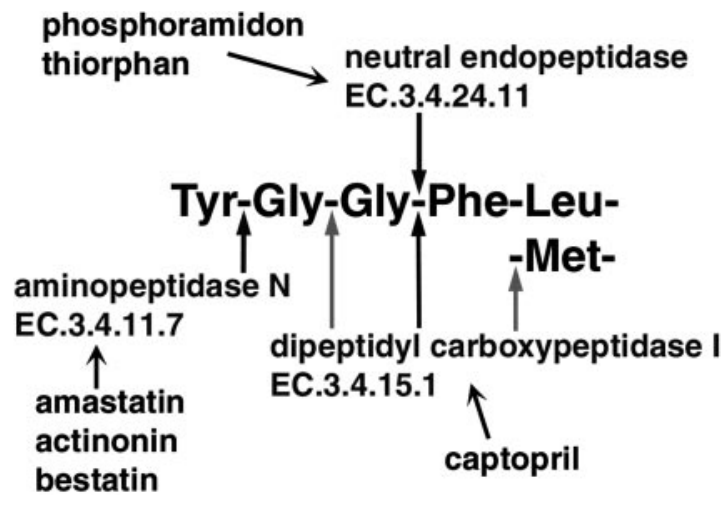

Figure 1. Opioid peptide bonds cleaved by peptidases. The $\mathrm{N}$-terminal sequence of opioids encoded by the proenkephalin, prodynorphin, and pro-opiomelanocortin genes is shown with arrows pointing to the bonds cleaved by the peptidases. Dipeptidyl carboxypeptidase I cleaves dipeptides sequentially from the $C$ terminal. Therefore, depending on whether the peptide has an odd (Met-enkephalin and Leu-enkephalin, dynorphin A) or even [Met-enk-Arg-Gly-Leu, dynorphin-(1-8)] number of amino acid residues, this peptidase would cleave the bonds indicated by the black or by the gray arrows, respectively (Guyon et al., 1979; Hiranuma et al., 1997 1998a,b). The peptidase inhibitors used in this study are shown with arrows pointing to their corresponding enzymes. Neutral endopeptidase is also known as enkephalinase, and dipeptidyl carboxypeptidase I has also been called angiotensin 1-converting enzyme and kininase II.

24216; DiaSorin, Stillwater, MN) and was characterized previously (Arvidsson et al., 1995). Cells labeled by this antibody are neurons (Spike et al., 2002). Although the MOR-1C and MOR-1D splice variants are not recognized by this antibody, they are present in primary afferent terminals and not in dorsal horn neurons (Abbadie et al., 2001). After three washes with PBS, sections were incubated for $2 \mathrm{hr}$ at room temperature with a secondary antibody (goat anti-rabbit IgG-Alexa-488; Molecular Probes, Eugene, OR) diluted 1:2000 in PBS/Triton. Sections were washed four more times with PBS and mounted in Prolong (Molecular Probes). Preabsorption of the MOR-1 antibody with its immunizing peptide (10 $\mu \mathrm{g} / \mathrm{ml}$ ) abolished the staining, and the labeling of MOR-1 in sections from slices was similar to sections from perfusion-fixed rats (Marvizon et al., 1999b).

Double-label immunohistochemistry. A similar procedure was used to double-label spinal cord sections for endomorphins, enkephalins, and MOR-1. Adult male rats were anesthetized with isoflurane, killed by bilateral thoracotomy, and fixed by aortal perfusion. Two spinal cord segments (L3-L2 and L4) were postfixed, cryoprotected, frozen, and sectioned at $25 \mu \mathrm{m}$ in the sagittal and coronal planes, respectively. Sections were incubated simultaneously with the two primary antibodies diluted in PBS/Triton containing 1\% normal serum for $1 \mathrm{hr}$ at room temperature and overnight at $4^{\circ} \mathrm{C}$. After three washes, sections were incubated simultaneously with the two secondary antibodies for $2 \mathrm{hr}$ at room temperature. The primary antibodies were the rabbit MOR-1 antibody described above, a mouse monoclonal antibody (3-E7) recognizing $\beta$-endorphin, enkephalins, and dynorphins (Gramsch Laboratories, Schwabhausen, Germany), a rabbit IgG (affinity-purified) raised against endomorphin-2 (catalog number AB5106; Chemicon, Temecula, CA), and a goat polyclonal antibody (affinity-purified) raised against the C-terminal of mouse MOR-1 (catalog number sc-7488; Santa Cruz Biotechnology, Santa Cruz, CA). Secondary antibodies were as follows: goat anti-rabbit IgG-Alexa-488 (Molecular Probes), goat anti-mouse IgGtetramethylrhodamine isothiocyanate, donkey anti-rabbit IgG-FITC, and donkey anti-goat IgG-rhodamine red-X (Jackson ImmunoResearch, West Grove, PA). All secondary antibodies produced negligible staining in the absence of primary antibody.

Antibody characterization. The 3-E7 mouse monoclonal antibody recognizes the N-terminal sequence Tyr-Gly-Gly-Phe-Met of $\beta$-endorphin and cross-reacts completely with Met-enkephalin and Leu-enkephalin and partially with dynorphins and $\alpha$-neoendorphin, as reported previously (Gramsch et al., 1983) and confirmed by us using preabsorption controls. Staining of the spinal cord with the 3-E7 antibody was unaf- 
fected by preabsorption with endomorphin-1 or endomorphin-2. The antibody directed against endomorphins recognized both endomorphin-1 (70\%) and endomorphin-2 (100\%) but not enkephalins or $\beta$-endorphin $(<0.03 \%)$, as reported by the manufacturer. Some antiendomorphin antibodies have been found to cross-react partially with calcitonin gene-related peptide (CGRP) (Pierce et al., 1998), probably because CGRP and endomorphins have the same C-terminal (Phe$\mathrm{NH}_{2}$ ). Staining of the dorsal horn by the endomorphin antibody was abolished by preabsorption with $1 \mu \mathrm{M}$ endomorphin-1 or endomorphin-2 but only slightly decreased by preabsorption with $1 \mu \mathrm{M}$ CGRP. Moreover, double-labeling of rat spinal cord sections with the endomorphin antibody and three different CGRP antibodies produced no colocalization (Marvizon and Song, 2002), indicating that this antibody does not cross-react with CGRP in our conditions. For doublelabeling with the rabbit anti-endomorphin antibody, we used a goat antibody directed against MOR-1. This antibody gave a somewhat less crisp label than the rabbit anti-MOR-1 antibody, and it had to be used at a higher concentration (1:200 dilution). When the two anti-MOR-1 antibodies were used together to double-label spinal cord sections, we found good colocalization.

Confocal microscopy and image processing. Confocal images were acquired at the University of California Los Angeles Carol Moss Spivak Cell Imaging Facility with a Leica (Nussloch, Germany) TCS-SP confocal microscope with argon (476 and $488 \mathrm{~nm}$ ) and krypton $(568 \mathrm{~nm})$ lasers, using a pinhole of 1.0 Airy units, and objectives of $10 \times(0.4$ numerical aperture $)$ or $100 \times(1.4$ numerical aperture), giving an optical section thickness (full width half maximum) of 8.13 and $0.62 \mu \mathrm{m}$, respectively. A zoom factor of 2 was used with some images taken at $100 \times$ to increase the pixel resolution of the resulting digital files. For each image at $100 \times$, stacks of 5-10 optical sections were obtained at intervals of 0.49 or $0.57 \mu \mathrm{m}$. Each optical section was averaged up
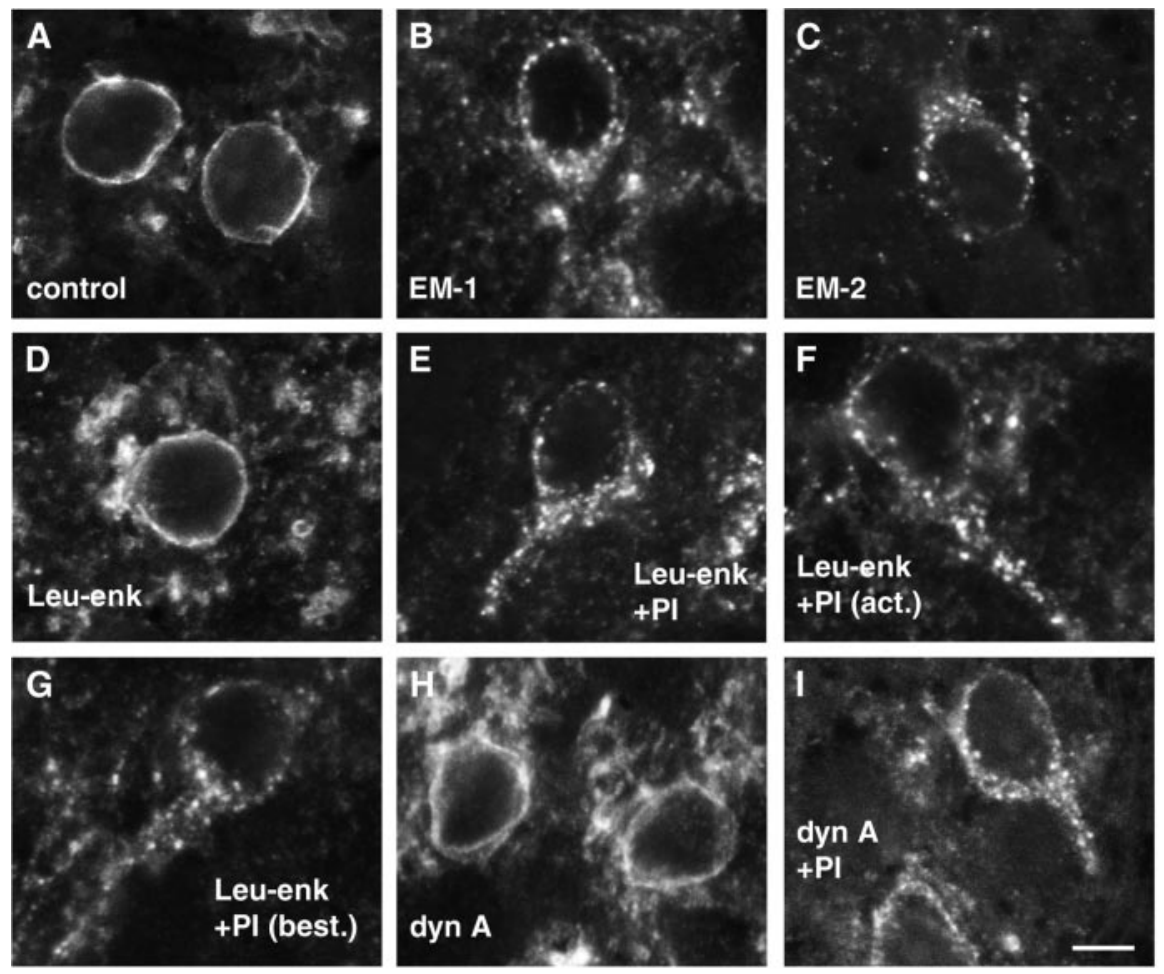

Figure 2. Confocal images of MOR-1 dorsal horn neurons exposed to opioids and peptidase inhibitors. Spinal cord slices were incubated for $20 \mathrm{~min}$ with opioids and peptidase inhibitors (PI; $10 \mu \mathrm{m}$ amastatin, captopril, and phosphoramidon). Treatments were as follows: Control $(A) ; 1 \mu \mathrm{m}$ endomorphin-1 (EM-1,B); $100 \mathrm{~nm}$ endomorphin-2 (EM-2, $) ; 1 \mu \mathrm{m}$ Leu-enkephalin (Leu-enk, D) $1 \mu \mathrm{m}$ Leu-enkephalin and peptidase inhibitors (E); $1 \mu \mathrm{m}$ Leu-enkephalin and peptidase inhibitors, $10 \mu \mathrm{m}$ actinonin (act.) instead of amastatin $(F) ; 1 \mu \mathrm{m}$ Leu-enkephalin and peptidase inhibitors, $100 \mu \mathrm{m}$ bestatin (best.) instead of amastatin (G); a $1 \mu \mathrm{m}$ concentration of dynorphin $\mathrm{A}(\operatorname{dyn} A, H)$; and $1 \mu \mathrm{m}$ dynorphin $\mathrm{A}$ and peptidase inhibitors $(I)$. Cells in $A, D$, and $H$ show no internalization; the rest show clear internalization. Dorsal is up for all panels except $H$, in which dorsal is right. Confocal images $(100 \times, z 00 m$ of 2) are two optical sections (three in $G$ and $H)$ through the center of lamina II neurons at intervals of 0.49 or 0.57 $\mu \mathrm{m}$, of five to seven optical sections. Scale bar: (in $/$ ) $A-l, 5 \mu \mathrm{m}$. to six times to reduce noise. Images were processed using Adobe Photoshop 5.5 (Adobe Systems, San Jose, CA). The "curves" feature of the program was used to adjust the contrast and to balance the colors of double-label images. were acquired at a digital size of $1024 \times 1024$ pixels and were later cropped to the relevant part of the field without altering the original image solution. tion was quantified essentially as described previously (Mantyh et al., 1995; Abbadie et al., 1997; Marvizon et al., 1997, 1999a,b; Trafton et al., (1R), by calculating the percentage of MOR-1 immunoreactive (IR) neurons in laminas I and II that show internalization in relation to (he person counting the neuCeiss, Inc., Thornwood, NY) fluorescence microscope fitted with orective lens was used to count neurons. Neuronal somata with At least three sections per slice were used, and all MOR-1 somata in these three sections were counted, representing 100-200 MOR-1 neurons per slice. An alternative method to quantify internalization consists of counting endosomes in confocal images of sample neurons for each treatmen 1999; Trafton et al., 2000). Although this method is more effective for examining the inside of individual neurons, it also has some se the selection of neurons to be imaged is a potential source of as the size of the neuronal body, the size and proximity of the membrane, and the number of dendrites present in the our method provides a better statistical base to discriminate subtle differences in the amount of internalization. In any event, similar results were obtained using these two methods (cf. Marvizon et al., 1999b; Trafton et al., 2000).

Statistical analysis. Treatments were randomized between slices, and no more than two slices from the same animal received the same treatment. Data were analyzed using GraphPad Prism version 3.03 for Windows (GraphPad Software, San Diego, CA). Statistical analyses consisted of one-way ANOVA followed by Tukey's post-test or two-way ANOVA followed by Bonferroni's post-test. Statistical significance was set at 0.05 . In concentration-response experiments, a sigmoidal doseresponse function, $Y=$ bottom + (top bottom $) /\left[1+10^{\exp }\left(\left[\log \mathrm{EC}_{50}-\log (X)\right] \times\right.\right.$ $\left.n_{\mathrm{H}}\right)$ ], where $n_{\mathrm{H}}$ denotes the Hill coefficient, was fitted to the data points by nonlinear regression. Data were simultaneously fitted to two models, one in which $n_{\mathrm{H}}$ was fixed to 1.0 , and the other in which $n_{\mathrm{H}}$ was calculated by the program. The second, more complex model was chosen based on an $F$ test if $p<0.005$. The "top" parameter was fixed to $100 \%$, because otherwise the regression often produced values $>100 \%$. The statistical error associated with the calculated $\mathrm{EC}_{50}$ was expressed as a $95 \%$ confidence interval $(95 \% \mathrm{CI})$.

\section{Results}

MOR-1 internalization produced by exogenously added opioids

It was initially observed that incubating spinal cord slices with relatively high concentrations $(1 \mu \mathrm{M})$ of Leu-enkephalin did not produce MOR-1 internalization. A confocal image of a representative neuron in a slice exposed to Leu-enkephalin is shown in Figure 2D: MOR-1 immunoreactivity was located at the surface of the 


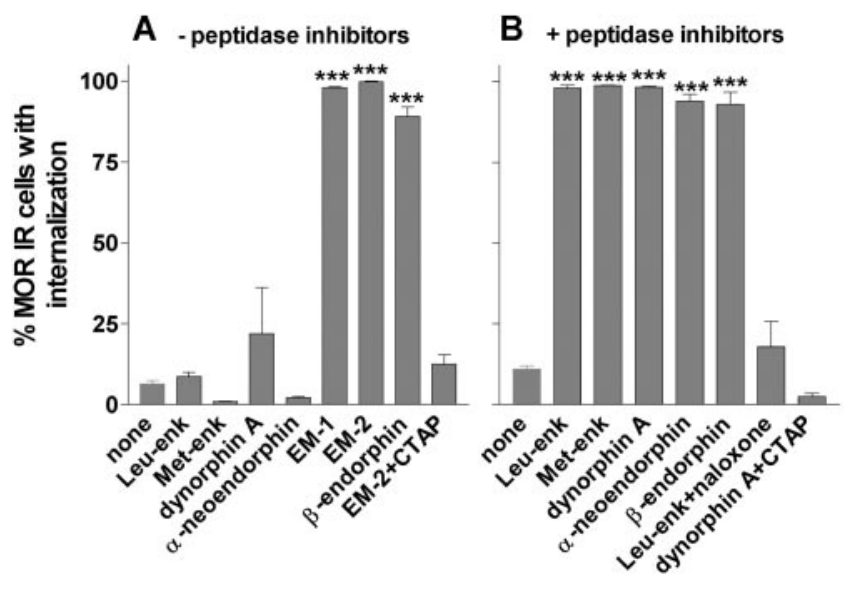

Figure 3. MOR-1 internalization produced by opioids with and without peptidase inhibitors. Spinal cord slices were incubated for 10 min without $(A)$ or with $(B)$ peptidase inhibitors and the opioids and opioid antagonists indicated. Peptidase inhibitors were $10 \mu \mathrm{m}$ amastatin, captopril, and phosphoramidon. Leu-enkephalin (Leu-enk), Met-enkephalin (Met-enk), $\alpha$-neoendorphin, endomorphin-1 (EM-1), $\beta$-endorphin, and CTAP were $1 \mu \mathrm{m}$; dynorphin A was $3 \mu \mathrm{m}$; endomorphin-2 (EM-2) was $0.1 \mu \mathrm{m}$; and naloxone was $10 \mu \mathrm{m}$. Columns represent the means \pm SEM of three to five slices (except none, which was 10 slices). Separate ANOVAs for $A$ and $B$ revealed overall significance $(p<0.0001)$. Tukey's post-test revealed the significant differences from none indicated by the asterisks ( $\left.{ }^{* * *} p<0.001\right)$ and significant differences $(p<0.001)$ between EM-2 and EM-2 + $\operatorname{CTAP}(A)$, Leu-enk and Leu-enk + naloxone $(B)$, and dynorphin $A$ and dynorphin $A+C \operatorname{CTP}(B)$.

somata, analogous to neurons in a control slice (Fig. 2 A). Similar results have been reported using Met-enkephalin (Trafton et al., 2000). In contrast, incubating slices with $1 \mu \mathrm{M}$ endomorphin-1 (Fig. $2 B$ ) or $0.1 \mu \mathrm{M}$ endomorphin-2 (Fig. $2 C$ ) produced extensive MOR-1 internalization in lamina II neurons. Although endomorphins have higher affinities for MOR-1 than enkephalins (Zadina et al., 1997), the affinity of Leu-enkephalin is sufficiently high to produce MOR-1 activation at $1 \mu \mathrm{M}$. We hypothesized that the inability of enkephalins to produce MOR-1 internalization when applied to spinal cord slices was attributable to their degradation by peptidases. In the guinea pig ileum and striatum, peptidases actively degrade enkephalins (Hiranuma and Oka, 1986, 1997, 1998a; Oka et al., 1986), but their degradation can be almost completely prevented by a mixture of three peptidase inhibitors: amastatin, captopril, and phosphoramidon (Fig. 1). Inhibitors of these peptidases also prevented the degradation of enkephalins released in the spinal cord (Chou et al., 1984; Yaksh and Chipkin, 1989). Indeed, when slices were incubated with this peptidase inhibitor mixture and Leu-enkephalin ( $1 \mu \mathrm{M})$, we observed profuse MOR-1 internalization in most MOR-1 neurons (Fig. 2E). Similarly, the degradation of dynorphin 1-8 in ileum and striatum was prevented by these protease inhibitors (Numata et al., 1988; Hiranuma et al., 1998b). We found that $1 \mu \mathrm{M}$ dynorphin A did not produce any MOR-1 internalization by itself (Fig. $2 \mathrm{H}$ ), but it elicited extensive MOR-1 internalization in the presence of the same peptidase inhibitor mixture (Fig. 2I).

These observations were quantified by counting MOR-1 neurons in laminas I-II with and without internalization (see Materials and Methods). In slices incubated with normal ACSF (Fig. $3 A$, none $)$ only a very small percentage $(6 \pm 1 \%)$ of MOR-1 neurons presented internalization. This percentage did not significantly increase in slices incubated with $1 \mu \mathrm{M}$ Leu-enkephalin or Met-enkephalin, $3 \mu \mathrm{M}$ dynorphin A, or $1 \mu \mathrm{M} \alpha$-neoendorphin (Fig. 3A). In contrast, $1 \mu \mathrm{M} \beta$-endorphin (rat sequence), $1 \mu \mathrm{M}$ endomorphin-1, and $0.1 \mu \mathrm{M}$ endomorphin-2 elicited MOR-1 internalization in a majority of MOR-1 neurons. MOR-1 internal- ization produced by endomorphin-2 was abolished in the presence of the selective MOR antagonist CTAP (D-Phe-Cys-TyrD-Trp-Arg-Thr-Pen-Thr- $\mathrm{NH}_{2}, 1 \mu \mathrm{M}$ ), showing that it was attributable to the binding of endomorphin-2 to MOR-1.

The opioid peptides that failed to produce MOR-1 internalization in the absence of peptidase inhibitors produced MOR-1 internalization in practically all MOR-1 IR neurons (Fig. 3B) in the presence of $10 \mu \mathrm{M}$ amastatin, captopril, and phosphoramidon. The peptidase inhibitor mixture by itself did not appreciably increase the percentage of MOR-1 neurons with internalization, as can be seen by comparing the none bars in Figure $3 A, B$ (also see below). MOR-1 internalization produced by $1 \mu \mathrm{M}$ Leuenkephalin was blocked by the opioid antagonist naloxone (10 $\mu \mathrm{M}$ ), and the MOR-1 internalization produced by $3 \mu \mathrm{M}$ dynorphin A was abolished by the selective MOR antagonist CTAP (1 $\mu \mathrm{M})$, indicating that it was mediated by the binding of the peptides to MOR. Selective agonists of $\delta$ and $\kappa$ opioid receptors did not elicit MOR-1 internalization in spinal cord slices (Marvizon et al., 1999b); therefore, it is highly unlikely that enkephalins and dynorphins produced MOR-1 internalization by interacting with $\delta$ and $\kappa$ receptors and not by binding directly to MOR-1.

\section{Peptidase inhibitors increased the potencies of Leu-enkephalin and dynorphin A to produce MOR-1 internalization}

The findings described above are consistent with our hypothesis that enkephalins and dynorphins are actively degraded by peptidases in the dorsal horn. The hypothesis also predicts that the inability of these opioids to produce MOR-1 internalization could be overcome at higher concentrations because they would saturate the peptidases, and that peptidase inhibitors would produce a left shift in their concentration-response curves to elicit MOR-1 internalization.

Figure $4 \mathrm{~A}$ shows that these predictions are fulfilled for Leuenkephalin. In the absence of peptidase inhibitors, high concentrations of Leu-enkephalin were able to produce MOR-1 internalization, yielding an $\mathrm{EC}_{50}$ of $22 \mu \mathrm{M}(95 \% \mathrm{CI}, 17-30)$. Peptidase inhibitors (amastatin, captopril, and phosphoramidon) dramatically shifted the concentration-response curve of Leuenkephalin to the left, increasing its potency by almost two orders of magnitude $\left(\mathrm{EC}_{50}, 0.38 \mu \mathrm{M} ; 95 \% \mathrm{CI}, 0.31-0.47\right)$. This $\mathrm{EC}_{50}$ value was very similar to the potency of Met-enkephalin $(0.25 \pm$ $0.6 \mu \mathrm{M}$ ) to produce outward currents in locus ceruleus neurons in the presence of the peptidase inhibitor kelatorphan (Williams et al., 1987). Figure $4 B$ shows that the predictions of the hypothesis are also satisfied for dynorphin A, although in this case the left shift of the concentration-response curve produced by peptidase inhibitors is less dramatic: the $\mathrm{EC}_{50}$ for dynorphin A decreased by one order of magnitude, from $5.2 \mu \mathrm{M}(95 \% \mathrm{CI}, 4.3-6.3)$ to 0.60 $\mu \mathrm{M}$ (95\% CI, 0.34-1.04). Hill coefficients calculated for the concentration-response curves were significantly higher than 1 (based on an $F$ test with $p<0.005$, see Statistical analysis, above) for Leu-enkephalin with peptidase inhibitors $\left(n_{\mathrm{H}}, 2.8 \pm 0.7\right)$ and for dynorphin A without peptidase inhibitors $\left(n_{\mathrm{H}}, 3.0 \pm 0.6\right)$. Using a less stringent criterion in the $F$ test $(p<0.05), n_{\mathrm{H}}$ was also $>1\left(n_{\mathrm{H}}, 1.8 \pm 0.5\right)$ for dynorphin A with peptidase inhibitors. These high Hill coefficients suggest the presence of positive cooperativity in processes that regulate the access of the opioids to the receptor or its internalization. The calculated $\mathrm{EC}_{50}$ values were fairly independent of $n_{\mathrm{H}}$ values. In the two cases in which $n_{\mathrm{H}}$ was $>1$, we obtained similar $\mathrm{EC}_{50}$ values if $n_{\mathrm{H}}$ was assumed to be 1: Leu-enkephalin with peptidase inhibitors: $\mathrm{EC}_{50}, 0.36 \mu \mathrm{M}(95 \%$ 


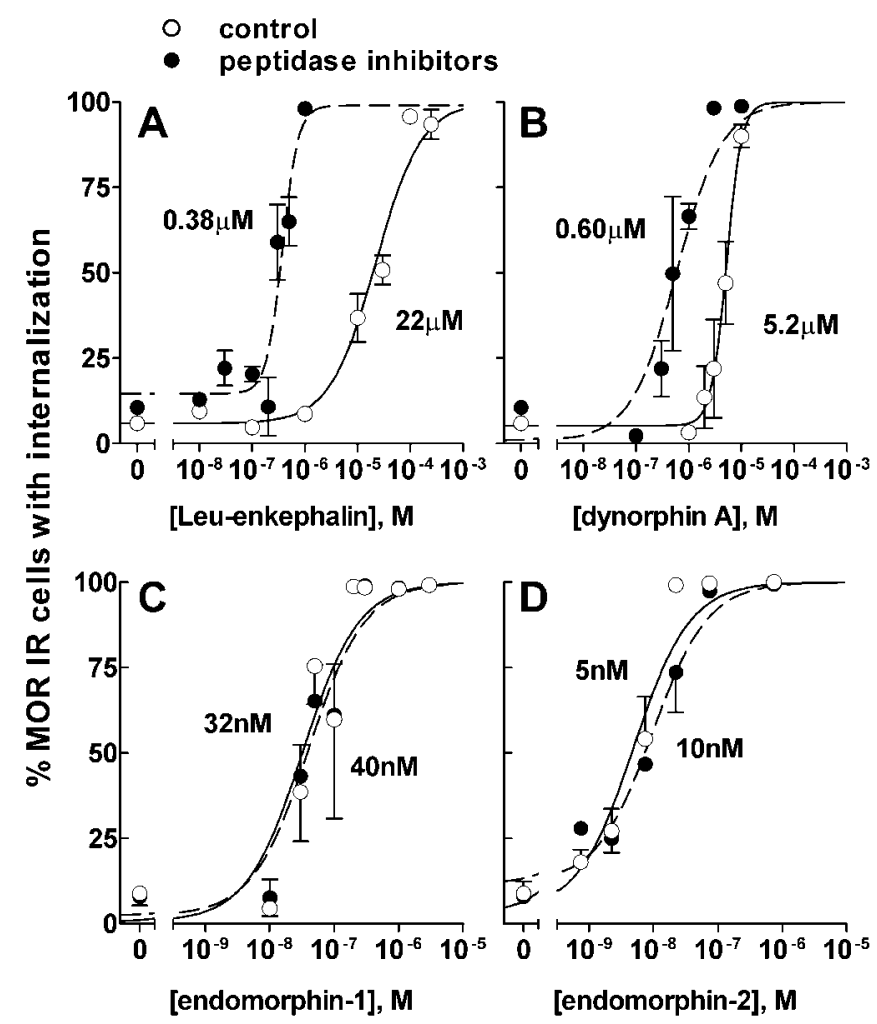

Figure 4. Effect of peptidase inhibitors on the potencies of Leu-enkephalin, dynorphin-A, endomorphin-1, and endomorphin-2 to produce MOR-1 internalization. Spinal cord slices were incubated for $10 \mathrm{~min}$ without (control) or with peptidase inhibitors, and the indicated concentrations of Leu-enkephalin $(A)$, dynorphin- $A(B)$, endomorphin-1 $(C)$, or endomorphin-2 (D). Peptidase inhibitors were $10 \mu \mathrm{m}$ amastatin, captopril, and phosphoramidon $(A, B)$, or these three inhibitors plus $10 \mu \mathrm{m}$ Ala-pyrrolidine-nitrile $(C, D)$. Points are the means \pm SEM of three to five slices. Curves were generated by fitting a sigmoidal dose-response curve to the data. Numbers next to the curves indicate $\mathrm{EC}_{50}$ values: $A$, Leu-enkephalin: $\mathrm{EC}_{50}, 22 \mu \mathrm{m}(95 \% \mathrm{Cl}$, $\left.17-30 ; R^{2}, 0.96\right)$; Leu-enkephalin (peptidase inhibitors): $\mathrm{EC}_{50}, 0.38 \mu \mathrm{M}(95 \% \mathrm{Cl}, 0.31-0.47$; $\left.n_{\mathrm{H}}, 2.8 \pm 0.7 ; R^{2}, 0.82\right)$. B, Dynorphin $\mathrm{A}: \mathrm{EC}_{50}, 5.2 \mu \mathrm{M}\left(95 \% \mathrm{Cl}_{1} 4.3-6.3 ; n_{\mathrm{H}}, 3.0 \pm 0.6 ; R^{2}\right.$, 0.90); dynorphin $\mathrm{A}$ (peptidase inhibitors): $\mathrm{EC}_{50}, 0.60 \mu \mathrm{M}\left(95 \% \mathrm{Cl}, 0.34-1.04 ; R^{2}, 0.83\right)$. $C$, Endomorphin-1: $\mathrm{EC}_{50}, 32 \mathrm{~nm}\left(95 \% \mathrm{Cl}, 16-65 ; R^{2}, 0.73\right)$; endomorphin-1 (peptidase inhibitors): $\mathrm{EC}_{50}, 40 \mathrm{~nm}\left(95 \% \mathrm{Cl}, 22-73 ; R^{2}, 0.77\right) . D$, Endomorphin-2: $\mathrm{EC}_{50}, 5 \mathrm{~nm}\left(95 \% \mathrm{Cl}, 3-8 ; R^{2}, 0.92\right)$; endomorphin-2 (peptidase inhibitors): $\mathrm{EC}_{50}, 10 \mathrm{~nm}\left(95 \% \mathrm{Cl}, 6-15 ; R^{2}, 0.94\right)$. Unless otherwise indicated, $n_{\mathrm{H}}$ values were fixed to 1.0 according to an $F$ test. Values of the top parameter were fixed to $100 \%$

CI, 0.20-0.64); dynorphin A without peptidase inhibitors: $\mathrm{EC}_{50}$, $4.6 \mu \mathrm{M}(95 \% \mathrm{CI}, 2.5-8.2)$.

\section{Peptidase inhibitors did not affect the potency of endomorphins to elicit MOR-1 internalization}

In contrast to the MOR-1 internalization produced by Leuenkephalin and dynorphin A, peptidase inhibitors had no effect on the potencies of endomorphin-1 (Fig. 4C) or endomorphin-2 (Fig. 4D) to elicit MOR-1 internalization. Because dipeptidyl peptidase IV (EC 3.4.14.15) has been reported to play an important role in degrading endomorphins (Shane et al., 1999), we included in the assay the dipeptidyl peptidase IV inhibitor Alapyrrolidine-nitrile (Li et al., 1995) $(10 \mu \mathrm{M})$ in addition to amastatin, captopril, and phosphoramidon. However, even with this addition the potency of endomorphin-1 was the same in the presence $\left(\mathrm{EC}_{50}, 40 \mathrm{nM} ; 95 \% \mathrm{CI}, 22-73\right)$ and in the absence $\left(\mathrm{EC}_{50}, 32\right.$ nм; 95\% CI, 16-65) of peptidase inhibitors. Likewise, the potency of endomorphin-2 was the same with $\left(\mathrm{EC}_{50}, 10 \mathrm{nM} ; 95 \% \mathrm{CI}\right.$, 6-15) and without $\left(\mathrm{EC}_{50}, 5 \mathrm{nM}\right.$; 95\% CI, 3-8) peptidase inhibi- tors. Diprotin A (Ile-Pro-Ile; $1 \mathrm{~mm}$ ), another dipeptidyl peptidase IV inhibitor, did not increase the MOR-1 internalization produced by $1 \mathrm{~nm}$ endomorphin-2 (control, $18 \pm 4 \%, n=3$; diprotin $\mathrm{A}, 8 \pm 3 \%, n=3$ ).

\section{Contribution of different peptidases to the degradation of Leu-enkephalin}

Next, we determined the relative contribution of peptidases to preventing MOR-1 internalization by Leu-enkephalin by using different combinations of peptidase inhibitors. We took advantage of the fact that Leu-enkephalin at $1 \mu \mathrm{M}$ elicited maximal MOR-1 internalization in the presence of peptidase inhibitors and minimal internalization in their absence (Fig. 4A). Hence, the ability of peptidase inhibitors to protect Leu-enkephalin against degradation would be reflected in the amount of MOR-1 internalization produced by $1 \mu \mathrm{M}$ Leu-enkephalin. Figure $5 \mathrm{~A}$ shows that in the presence of $10 \mu \mathrm{M}$ amastatin, phosphoramidon, or captopril alone, or even combined two by two, $1 \mu \mathrm{M}$ Leuenkephalin remained unable to significantly stimulate MOR-1 internalization. These results indicate that each of the three peptidases targeted by these inhibitors (aminopeptidases, neutral endopeptidase, and dipeptidyl carboxypeptidase) (Fig. 1) is sufficient to degrade Leu-enkephalin substantially. Interpolating the data in Figure $5 A$ in the left curve of Figure $4 A$ suggests that each of these peptidases is able to reduce the concentration of Leuenkephalin from 1 to $<0.3 \mu \mathrm{M}$. Thiorphan, like phosphoramidon, inhibits neutral endopeptidase (Yaksh and Chipkin, 1989). In the presence of $10 \mu \mathrm{M}$ thiorphan, amastatin, and captopril, 1 $\mu \mathrm{M}$ Leu-enkephalin did produce significant MOR-1 internalization (Fig. 5A), although the effect was not as consistent as in the presence of phosphoramidon.

To further characterize the aminopeptidase(s) responsible for the degradation of enkephalins in the spinal cord, we substituted different aminopeptidase inhibitors for amastatin in our inhibitor mixture (Fig. 5B). Antipain, arphamenine, bacitracin, proctolin, and puromycin were ineffective. Other studies found that bacitracin (Tseng et al., 1986; Ozaki et al., 1994) and puromycin (Aoki et al., 1984) did not protect enkephalins against degradation. Only actinonin (Fig. $1 F$ ) and amastatin (Fig. $1 E$ ) protected the effect of Leu-enkephalin at $10 \mu \mathrm{M}$. The effectiveness of amastatin was reduced at $1 \mu \mathrm{M}$ but remained significant. Amastatin inhibits aminopeptidases N (EC 3.4.11.7), A (EC 3.4.11.2), and $\mathrm{W}$ (EC 3.4.11.16), with $\mathrm{IC}_{50}$ values of 1-20 $\mu \mathrm{M}$, whereas actinonin inhibits aminopeptidase $\mathrm{N}\left(\mathrm{IC}_{50}, 2 \mu \mathrm{M}\right)$ but not aminopeptidases A and W (Tieku and Hooper, 1992). Bestatin was ineffective at $10 \mu \mathrm{M}$ but protected the effect of Leu-enkephalin at $100 \mu \mathrm{M}$ (Fig. 1G). Bestatin potently inhibits aminopeptidase W $\left(\mathrm{IC}_{50}, 8 \mu \mathrm{M}\right)$, inhibits aminopeptidase $\mathrm{N}$ at higher concentrations $\left(\mathrm{IC}_{50}, 89 \mu \mathrm{M}\right)$, and does not inhibit aminopeptidase A (Tieku and Hooper, 1992; Suzuki et al., 1997). Together, these results show that the pharmacological profile of the aminopeptidase that degrades Leu-enkephalin matches that of aminopeptidase N.

\section{Contribution of different peptidases to the degradation of dynorphin A}

The effect of combinations of peptidase inhibitors on dynorphin A (Fig. 5C) was different from their effect on Leu-enkephalin (Fig. 5A). Amastatin plus phosphoramidon was as effective as all three peptidase inhibitors in protecting the effect of dynorphin A, indicating that dynorphin $\mathrm{A}$ is degraded by aminopeptidases and neutral endopeptidase. Moreover, significant $(p<0.05)$ protection could be achieved with amastatin alone. Actinonin could substitute for amastatin, which is consistent with the idea that 
aminopeptidase $\mathrm{N}$ is involved in the degradation of dynorphins as well as enkephalins. No protection of dynorphin A was obtained with phosphoramidon plus captopril, and the addition of captopril did not increase the effect of amastatin, which shows that the MOR-1 internalization produced by dynorphin A is not appreciably decreased by dipeptidyl carboxypeptidase. This is probably attributable to the fact that dipeptidyl carboxypeptidase starts cleaving dynorphin $\mathrm{A}$ at its extended $\mathrm{C}$ terminal (Fig. 1 ), producing peptides containing the Leu-enkephalin sequence that are still able to activate MOR-1.

\section{Relative localization of opioid peptides and MOR-1 in the dorsal horn}

The localization of opioid-containing terminals relative to MOR-1 IR neurons was explored using double-label immunofluorescence. To detect opioid peptides, we used a monoclonal antibody (3-E7) that recognized $\beta$-endorphin, enkephalins, dynorphins, and $\alpha$-neoendorphin (Gramsch et al., 1983) but not endomorphins (data not shown). Costaining with the 3-E7 and the MOR-1 antibodies (Fig. $6 \mathrm{~A}$ ) showed that 3-E7 IR is very dense in laminas I and II, where MOR-1 IR cells were located, and also slightly deeper in the dorsal horn and in the dorsolateral funiculus, where MOR-1 staining was absent. High-magnification confocal images in sagittal sections (Fig. 6B) showed that 3-E7 IR terminals are dispersed around MOR-1 IR neurons and dendrites. Some 3-E7 IR terminals were in close apposition with MOR-1 IR neurons or colocalized with it (Fig. $6 B$, arrows), indicating the presence of synapses and presynaptic MOR-1.

Using an antibody that recognizes endomorphin-1 and endomorphin-2, we found that endomorphin-like immunoreactivity did not colocalize with 3-E7 immunoreactivity (data not shown), suggesting that endomorphins are contained in terminals different from other opioids. Endomorphin-like immunoreactivity was found primarily in lamina I and the dorsolateral funiculus, whereas most MOR-1 IR neurons were found in lamina II (Fig. 6), separated from endomorphin IR fibers and varicosities (data not shown). However, Spike et al. (2002) recently reported that endomorphin-2 was present in substance-Pcontaining axons contacting MOR-1 neurons in the dorsal horn.

\section{MOR-1 internalization produced by endogenously released opioids}

To elicit opioid release, spinal cord slices were incubated with 30 $\mu \mathrm{M}$ veratridine or $50 \mathrm{~mm} \mathrm{KCl}$ in the presence or absence of peptidase inhibitors (amastatin, captopril, and phosphoramidon). Veratridine increases $\mathrm{Na}^{+}$fluxes through voltage-dependent $\mathrm{Na}^{+}$channels (Satoh and Nakazato, 1991). These stimuli have been shown previously to elicit Met-enkephalin (Uzumaki et al., 1984; Yaksh and Chipkin, 1989) and dynorphin (Przewlocka et al., 1990) release from the spinal cord.

A short $(2 \mathrm{~min})$ incubation with $30 \mu \mathrm{M}$ veratridine in the presence of peptidase inhibitors produced MOR-1 internalization in approximately two-thirds of MOR-1 IR cells (Fig. 7A).
However, veratridine did not produce MOR-1 internalization in the absence of peptidase inhibitors. These data were analyzed with a two-way ANOVA with veratridine and peptidase inhibitors as the two variables, which showed significant $(p<0.0001)$ effects of the variables and their interaction. Bonferroni's posttest revealed a significant effect $(p<0.001)$ of veratridine combined with peptidase inhibitors but no significant effects of peptidase inhibitors alone or veratridine without peptidase inhibitors.

Depolarization with high $\mathrm{K}^{+}$in the presence of peptidase inhibitors elicited MOR-1 internalization in one-third of the MOR-1 IR neurons (Fig. 8A). In this experiment, slices were incubated for $20 \mathrm{~min}$ in ACSF containing $50 \mathrm{~mm} \mathrm{KCl}$, decreasing the concentration of $\mathrm{NaCl}$ by the same amount to avoid increasing the osmotic pressure. In the absence of peptidase inhibitors, $50 \mathrm{~mm} \mathrm{KCl}$ produced MOR-1 internalization in a small percentage of MOR-1 IR neurons (Fig. 8 A). Two-way ANOVA revealed significant effects of the variables high $\mathrm{K}^{+}$and peptidase inhibitors $(p<0.0001)$ and their interaction $(p<0.01)$. Bonferroni's post-test yielded a significant effect for $50 \mathrm{~mm} \mathrm{KCl}$ without $(p<$ $0.05)$ and with $(p<0.001)$ peptidase inhibitors.

Confocal images of neurons representative of these observations are shown in Figure 9. Neurons exposed to peptidase inhibitors $(A)$ or veratridine $(B)$ alone showed crisp surface staining and no endosomes. Figure $9 F$ shows a neuron exposed to $50 \mathrm{~mm}$ $\mathrm{KCl}$ in the absence of peptidase inhibitors; it presents a somewhat discontinuous labeling of the membrane, possibly indicating some MOR-1 clustering. In the presence of peptidase inhibitors, veratridine produced clear internalization in most neurons, as shown by the group of three neurons in Figure $9 C$. The neuron in the bottom left corner does not have the nucleus in the confocal plane, and part of a fourth neuron is visible in the bottom right corner. Note the presence of intensely labeled endosomes and the decrease in surface staining. Figure $9 G$ shows a neuron presenting internalization after treatment with high $\mathrm{K}^{+}$and peptidase in- 

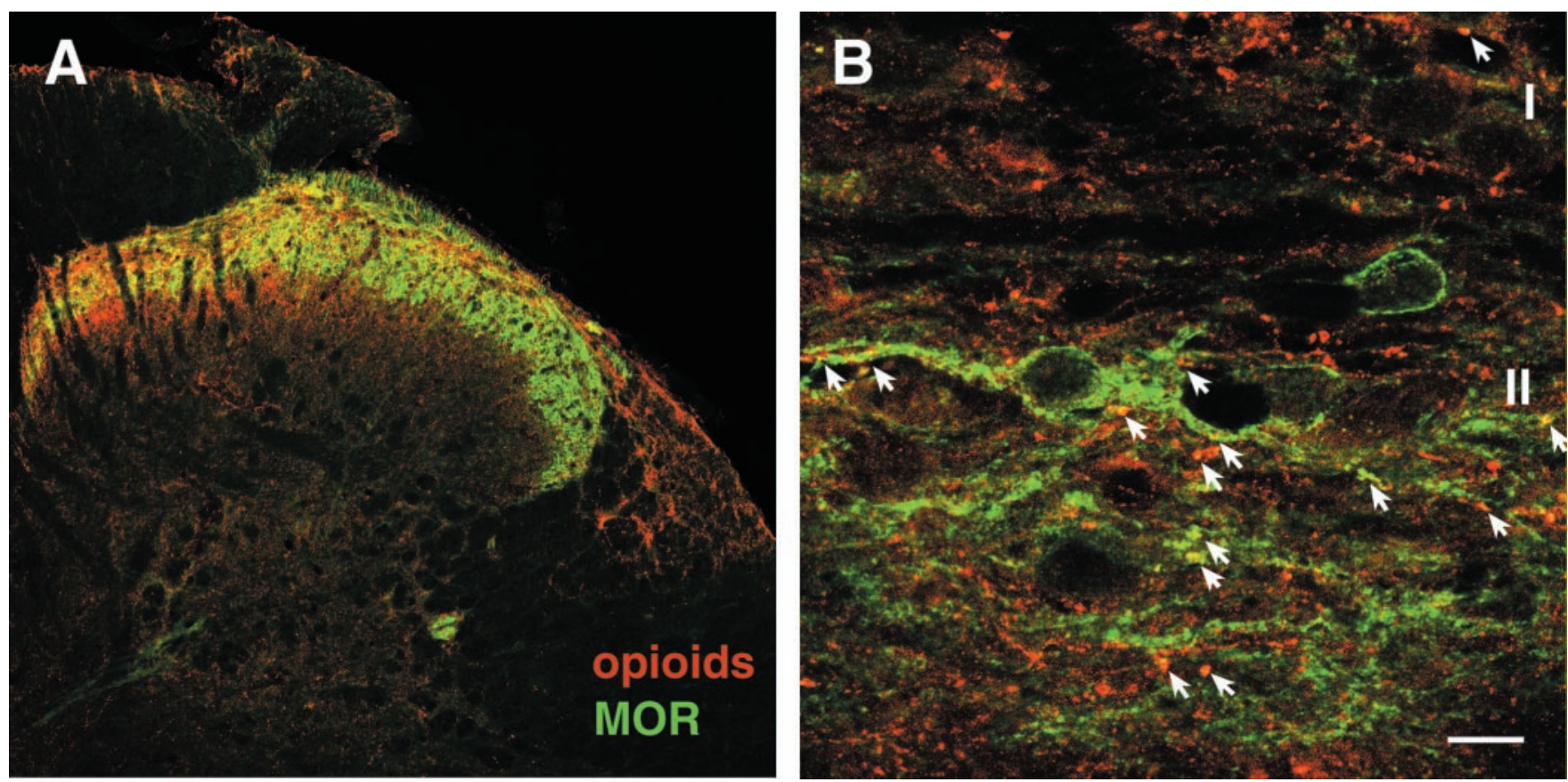

Figure 6. Relative localization of opioids and MOR-1 in the dorsal horn. Sections $(25 \mu \mathrm{m})$ from the lumbar spinal cord of an adult rat were double-labeled with a monoclonal antibody (3-E7) recognizing enkephalins, $\beta$-endorphin, dynorphins, and $\alpha$-neoendorphin (opioids, red), and the MOR-1 antibody (MOR, green). $A$, Single optical section at $10 \times$ magnification from a coronal section. $B$, Two optical sections at $100 \times$ magnification from a sagittal section. Arrows indicate sites of possible colocalization (in yellow). I and II, Approximate location of laminas I and II, respectively. Scale bar: (in $B) A, 100 \mu \mathrm{m} ; B, 10 \mu \mathrm{m}$.

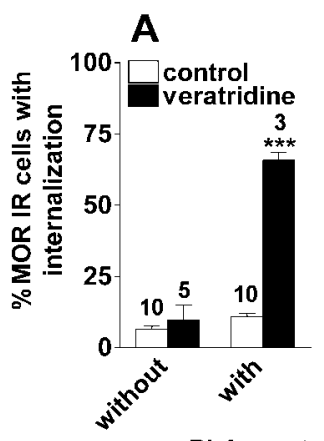

ama+PhA+capt
B

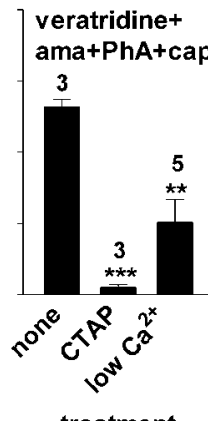

treatment
C

veratridine

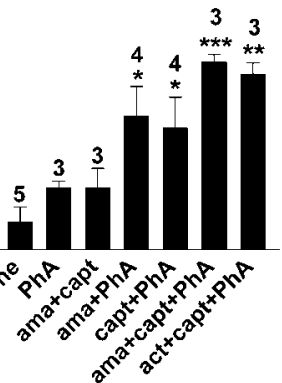

peptidase inhibitors

Figure 7. MOR-1 internalization produced by opioids released by veratridine. All compounds were applied to the slices during a 2 min incubation with $30 \mu \mathrm{m}$ veratridine and for $10 \mathrm{~min}$ afterward. Peptidase inhibitors (10 $\mu \mathrm{m}$ ) were actinonin (act), amastatin (ama), captopril (capt), and phosphoramidon (PhA). Numbers above the columns indicate the number of replicates (slices). A, Slices were incubated in ACSF (control) or $30 \mu \mathrm{m}$ veratridine, without or with peptidase inhibitors. Two-way ANOVA indicated significant ( $p<0.0001$ ) effects of both variables (veratridine and peptidase inhibitors) and their interaction. Bonferroni's post-test indicated significant differences from control only for veratridine with peptidase inhibitors $\left({ }^{* * *} p<0.001\right)$. $B$, Slices were treated with veratridine, peptidase inhibitors, and no addition (none), $10 \mu \mathrm{m}$ CTAP, or $0.2 \mathrm{~mm} \mathrm{CaCl}_{2}\left(\right.$ low $\left.\mathrm{Ca}^{2+}\right)$. ANOVA, $p=0.0001$ overall; Tukey's post-test, ${ }^{* * *} p<0.001$; ${ }^{* *} p<0.01$ compared with none. C, Slices were incubated with veratridine and the indicated combinations of peptidase inhibitors. ANOVA, $p=0.0006$ overall; Tukey's post-test, ${ }^{*} p<0.05$; ${ }^{* *} p<0.01$ compared with none.

hibitors. This neuron has a nucleus occupying most of the soma, which is common in MOR-1 IR neurons in the dorsal horn (see also Figs. 2, 6B). However, there is almost no surface staining, and several endosomes are visible in the cytoplasm and along one dendrite.

The selective MOR-1 antagonist CTAP ( $1 \mu \mathrm{M})$ abolished MOR-1 internalization produced by veratridine (Fig. $7 B$ ) or 50

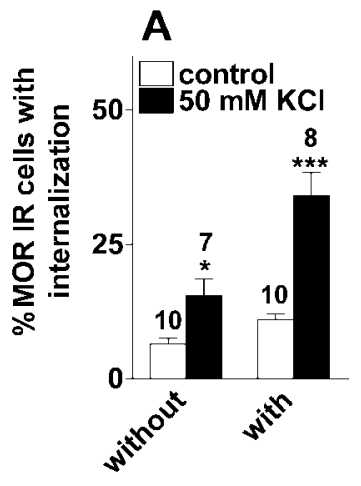

ama+PhA+capt
B

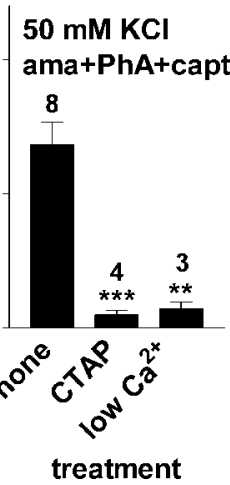

C

$50 \mathrm{mM} \mathrm{KCl}$

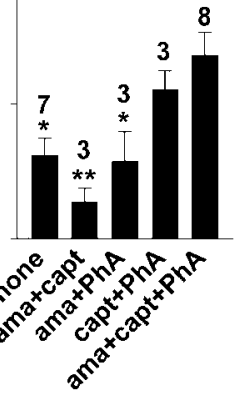

Figure 8. MOR-1 internalization produced by opioids released by $50 \mathrm{~mm} \mathrm{KCl}$. Spinal cord slices were incubated for $20 \mathrm{~min}$ with $50 \mathrm{~mm} \mathrm{KCl}$, peptidase inhibitors, and other additions. Peptidase inhibitors $(10 \mu \mathrm{M})$ were amastatin (ama), phosphoramidon (PhA), and captopril (capt). Numbers above the columns indicate the number of replicates (slices). A, Slices were incubated in normal ACSF (control) or in ACSF containing $50 \mathrm{~mm} \mathrm{KCl}$, without or with peptidase inhibitors. Control values are the same as in Figure $7 A$, and are shown here for comparison. Two-way ANOVA with $50 \mathrm{~mm} \mathrm{KCl}$ and peptidase inhibitors as the variables indicated significant $(p<0.0001)$ effects of both variables and their interaction $(p<0.01)$. Bonferroni's post-test indicated significant differences from controls for $50 \mathrm{~mm} \mathrm{KCl}$ both without $\left({ }^{*} p<0.05\right.$ ) and with $\left({ }^{* * *} p<0.001\right)$ peptidase inhibitors. B, Slices were incubated in ACSF containing $50 \mathrm{~mm} \mathrm{KCl}$, peptidase inhibitors, and no other addition (none), $1 \mu \mathrm{M}$ (TAP, or $0.2 \mathrm{~mm} \mathrm{CaCl}\left(\mathrm{Ilow} \mathrm{Ca}^{2+}\right)$. ANOVA, $p<0.0001$ overall; Tukey's post-test, ${ }^{* *} p<0.01$; ${ }^{* * *} p<0.001$ compared with none. C, Slices were incubated in ACSF containing $50 \mathrm{~mm} \mathrm{KCl}$ and the indicated combinations of peptidase inhibitors. ANOVA, $p=0.0017$ overall; Tukey's post-test, ${ }^{* *} p<0.01$; ${ }^{*} p<0.05$ compared with ama + capt + PhA.

mM KCl (Fig. $8 A$ ) in the presence of peptidase inhibitors. Representative neurons are shown in Figure $9 D$ (veratridine) and Figure $9 \mathrm{H}\left(\right.$ high $\left.\mathrm{K}^{+}\right)$. This observation indicates that the internalization was attributable to the interaction of agonists with 
MOR-1. Moreover, if the internalization produced by veratridine and high $\mathrm{K}^{+}$was attributable to the release of endogenous opioids, we predicted that it would be inhibited in the absence $\mathrm{Ca}^{2+}$ as well. However, it is possible that the mechanism of MOR-1 internalization itself requires $\mathrm{Ca}^{2+}$. Indeed, in the nominal absence of $\mathrm{Ca}^{2+}$ (no $\mathrm{CaCl}_{2}$ was added), the MOR-1 internalization produced by $1 \mu \mathrm{M}$ endomorphin-2 was decreased from $100 \%$ of MOR-1 neurons with internalization (Fig. $4 D)$ to $55 \pm 18 \%(n=5)$. However, a 10-fold reduction in $\mathrm{Ca}^{2+}$ concentration (from 2.4 to $0.2 \mathrm{~mm}$ ) did not affect the MOR-1 internalization produced by $0.1 \mu \mathrm{M}$ endomorphin-2, which was present in $97 \pm 2 \%$ of the MOR- 1 IR neurons $(n=3)$. Therefore, the MOR-1 internalization process can take place if a small amount of $\mathrm{Ca}^{2+}$ is present in the extracellular medium. Yet when the $\mathrm{Ca}^{2+}$ concentration was decreased to $0.2 \mathrm{~mm}$, the MOR-1 internalization produced by $50 \mathrm{~mm} \mathrm{KCl}$ (Figs. 7A, 8I) or veratridine (Figs. 6B, 8E) was abolished or greatly reduced, respectively. These results confirm that veratridine and high $\mathrm{K}^{+}$produced MOR-1 internalization by eliciting the $\mathrm{Ca}^{2+}$-dependent release of endogenous opioids.

\section{Contribution of different peptidases to the degradation of endogenously released opioids}

To determine which peptidases contributed to the degradation of the opioids released by veratridine or high $\mathrm{K}^{+}$, we studied the effect of different combinations of peptidase inhibitors. In the case of high $\mathrm{K}^{+}$(Fig. $8 \mathrm{~B}$ ), only the mixture of the three inhibitors significantly increased $(p<0.05)$ MOR-1 internalization above that produced by $50 \mathrm{~mm} \mathrm{KCl}$ alone. However, phosphoramidon plus captopril produced an effect that was not significantly different from the combination of the three inhibitors, and showed a trend toward increased internalization. In the case of veratridine (Fig. 7C), phosphoramidon plus captopril or phosphoramidon plus amastatin produced MOR-1 internalization significantly above control levels $(p<0.05)$. However, phosphoramidon by itself or amastatin plus captopril did not significantly increase internalization above the effect of veratridine alone. Mixtures of three inhibitors, including either amastatin or actinonin as aminopeptidase inhibitors, produced robust MOR-1 internalization $(p<0.01)$. These results indicate that neutral endopeptidase is the main enzyme degrading opioids released in the spinal cord, with a substantial contribution of aminopeptidases and dipeptidyl carboxypeptidase.

\section{Discussion}

In summary, in the dorsal horn: (1) peptidases restrict MOR-1 internalization by exogenously applied enkephalins and dynorphins, (2) endomorphins are not substantially degraded by peptidases, and (3) peptidases prevent MOR-1 internalization by endogenously released opioids.
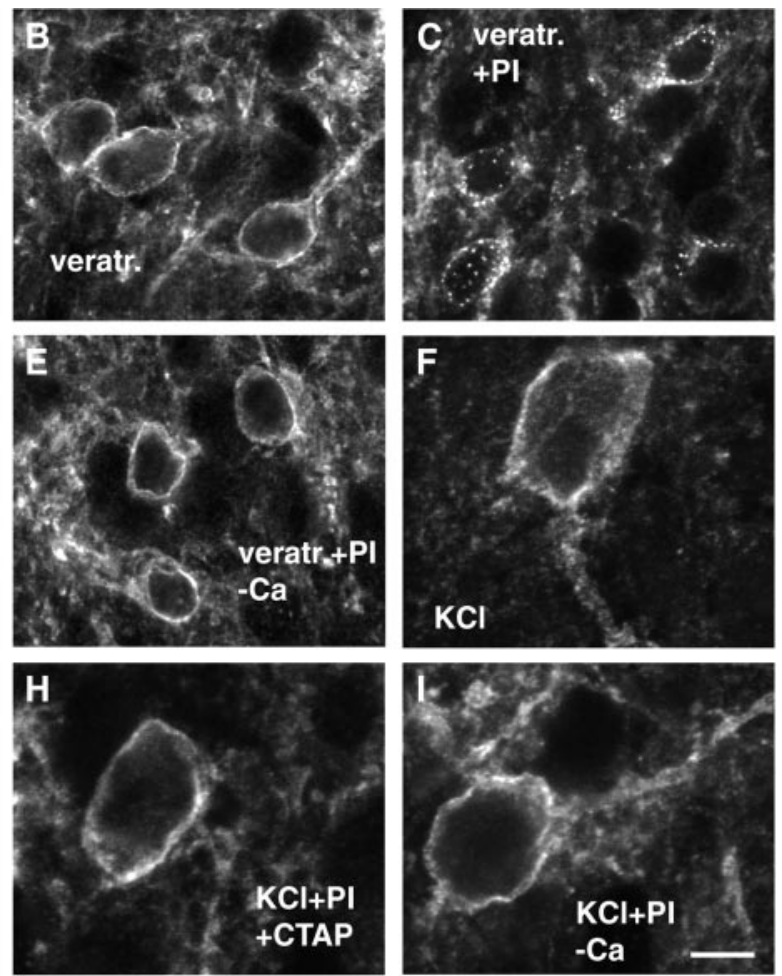

Figure 9. Confocal images of MOR-1 dorsal horn neurons treated with $50 \mathrm{~mm} \mathrm{KCl}$ or veratridine. Slice treatments were as follows: peptidase inhibitors $(P I)$ alone $(A) ; 30 \mu \mathrm{m}$ veratridine (veratr., $B) ; 30 \mu \mathrm{m}$ veratridine and peptidase inhibitors $(C) ; 30 \mu \mathrm{M}$ II. Dorsal is up for all panels. For each image, stacks of 5-10 optical sections were obtained at intervals of 0.49 or $0.57 \mu \mathrm{m}$, but only two optical sections ( 3 for $A$ and $C, 4$ for $G$ ) through the center of the cell are shown. Scale bar: (in $/$ ) $A, F-I, 5 \mu \mathrm{m} ; B-E, 10 \mu \mathrm{m}$.

\section{Peptidases restrict MOR-1 internalization by exogenous enkephalins and dynorphins}

Peptidase inhibitors substantially increased the potencies of Leuenkephalin and dynorphin A to elicit MOR-1 internalization, as well as the effect of single concentrations of Met-enkephalin and $\alpha$-neoendorphin, indicating that three peptidases (Fig. 1) cleave enkephalins and dynorphins before they bind to MOR. Opioids encoded by the proenkephalin, prodynorphin, and proopiomelanocortin genes have $\mathrm{N}$ terminals homologous to Leuenkephalin or Met-enkephalin and are in principle susceptible to be cleaved by these peptidases. However, $\beta$-endorphin produced MOR-1 internalization in the absence of peptidase inhibitors, probably because its tertiary structure protects against cleavage by aminopeptidases (Bewley and Li, 1985), its long sequence provides protection against carboxypeptidases, and neutral endopeptidase preferentially cleaves the Leu17-Phe18 bond (Graf et al., 1985), producing $\gamma$-endorphin. Indeed, many degradation products of $\beta$-endorphin are biologically active (Burbach and De Kloet, 1982).

All three peptidases degraded Leu-enkephalin, because omission of any one inhibitor resulted in the loss of its effect. The Leu-enkephalin-degrading aminopeptidase was probably aminopeptidase N (Tieku and Hooper, 1992; Suzuki et al., 1997) present in the dorsal horn (Noble et al., 2001), because it was inhibited by amastatin, actinonin, and high concentrations of bestatin, but not by puromycin or other aminopeptidase inhibitors. Aminopeptidase M degrades enkephalins (Hersh, 1985) but is located primarily in blood vessels (Hersh et al., 1987), and other 
enkephalin-degrading aminopeptidases are sensitive to puromycin (Shimamura et al., 1983; Dyer et al., 1990; Hui et al., 1998). However, we cannot rule out the involvement of aminopeptidases with a pharmacological profile similar to aminopeptidase $\mathrm{N}$, like one associated with opioid receptors (Hui et al., 1985).

The ability of dynorphin A to produce MOR-1 internalization was decreased by aminopeptidases and neutral endopeptidase, but not appreciably by dipeptidyl carboxypeptidase, probably because their cleavage of dynorphin A produces active peptides containing the Leu-enkephalin sequence. Likewise, although dynorphin A does have a fairly high affinity for MOR-1 (Raynor et al., 1993; Zadina et al., 1997), we cannot rule out that MOR-1 internalization produced by dynorphin A was mediated through its conversion to Leu-enkephalin by peptidase EC 3.4.24.15 (Bell and Traynor, 1998). Importantly, in the absence of peptidase inhibitors, dynorphin A was more potent than Leu-enkephalin in producing MOR-1 internalization.

\section{Endomorphin-1 and endomorphin-2 are not degraded by peptidases}

Shane et al. (1999) showed that ventricular administration of an inhibitor of dipeptidyl peptidase IV enhanced the analgesic effect of endomorphin-2. In contrast, we found that inhibitors of this and other peptidases did not affect the abilities of endomorphins to produce MOR-1 internalization. It is possible that dipeptidyl peptidase IV activity in the dorsal horn is lower than in the brain. However, Tomboly et al. (2002) showed that endomorphins are degraded at slow rates in the brain. Unlike endomorphins, the opioids released by veratridine or high $\mathrm{K}^{+}$were degraded by peptidases. It is possible that the marginal internalization elicited in the absence of peptidase inhibitors by high $\mathrm{K}^{+}$(but not veratridine) was attributable to endomorphin release, but it could also be mediated by $\beta$-endorphin. Therefore, endomorphins, despite their high affinity, seem to contribute little to the activation of extrasynaptic MOR-1 in dorsal horn neurons.

\section{Endogenously released opioids}

The MOR-1 internalization produced by veratridine or high $\mathrm{K}^{+}$ was abolished by the MOR-1 antagonist CTAP and was $\mathrm{Ca}^{2+}$ dependent, indicating that it was attributable to the release of MOR-1 agonists. Veratridine-evoked MOR-1 internalization required peptidase inhibitors, and internalization produced by high $\mathrm{K}^{+}$was greatly reduced in their absence, showing that most of the released opioids are degraded by peptidases. This is consistent with studies showing that peptidase inhibitors decreased ventral root potentials (Suzuki et al., 1997) and responses of dorsal horn neurons to C fiber activity (Dickenson et al., 1987).

Neutral endopeptidase appears to be the main enzyme degrading released opioids, because phosphoramidon plus amastatin or captopril, but not amastatin plus captopril, protected the effect of veratridine. However, phosphoramidon alone did not produce significant protection, indicating that the contribution of aminopeptidases and dipeptidyl carboxypeptidase is also important. In contrast, the internalization produced by Leuenkephalin was similarly decreased by all three peptidases, whereas the effect of dynorphin A was not decreased by dipeptidyl carboxypeptidase. This discrepancy suggests that the opioids released are not the enkephalin pentapeptides or dynorphin A alone, but a mixture of opioid peptides of various lengths (Lucas and Yaksh, 1990), resulting in a mixed susceptibility to peptidases.

Our results show that MOR-1 internalization can be used to investigate mechanisms of opioid release. Opioids are not appre- ciably released from primary afferents, because prolonged dorsal root stimulation while superfusing the slices with peptidase inhibitors did not produce MOR-1 internalization (Marvizon and Song, 2002). Therefore, the opioid release detected here is probably from interneurons (Todd and Spike, 1993) and/or bulbospinal fibers (Basbaum and Fields, 1984; Le Bars et al., 1987b; Fields et al., 1991; Budai and Fields, 1998).

\section{Physiological relevance}

Our results likely reflect the situation in vivo. Amastatin, captopril, and phosphoramidon increased the analgesic effects of intrathecal or intracerebral opioids (Kishioka et al., 1994; Kitamura et al., 2000), but deletion of any one of the inhibitors substantially decreased this effect. The peptidase inhibitor RB-101 $[N-([R, S]-$ 2-benzyl-3([S] [2-amino-4-methythio]butyl dithio)-1-oxopropyl)-Lphenylalanine benzyl ester] injected systemically also produced analgesia (Noble et al., 1992a).

The relationship between MOR activation and its internalization is complex. Although internalization requires activation, the converse is not always true, because morphine activates MOR-1 without producing its internalization (Keith et al., 1998). Nevertheless, it has been suggested that endogenous opioids are able to produce MOR-1 internalization (Whistler et al., 1999). Our results support this idea, because all of the opioids tested produced MOR-1 internalization. Moreover, in the presence of peptidase inhibitors, the potency of Leu-enkephalin to produce MOR-1 internalization was remarkably similar to the potency of Metenkephalin to evoke outward currents in locus ceruleus neurons (Williams et al., 1987). Therefore, MOR-1 internalization provides a good indicator of its activation by endogenous opioids.

In view of this, it is puzzling that noxious stimuli that elicited spinal enkephalin release (Yaksh and Elde, 1981; Cesselin et al., 1985; Le Bars et al., 1987a,b; Cesselin et al., 1989; Bourgoin et al., 1990) did not produce MOR-1 internalization in dorsal horn neurons (Trafton et al., 2000). We show here that this was probably because of opioid degradation, but the question remains as to why peptidases did not degrade opioids detected in release studies that did not use peptidase inhibitors. However, in other studies (Yaksh and Chipkin, 1989) peptidase inhibitors did produce a 10-fold increase in Met-enkephalin release. Peptidases are bound to the extracellular surface of neurons (Aoki et al., 1984; Roques, 2000) and may be associated with MOR (Hui et al., 1985), degrading opioids in their microenvironment. Thus, opioids diffusing away from the tissue would not be degraded as readily as those near the receptors. Conversely, exogenous opioids will be degraded as they approach MOR-1.

Our findings indicate that opioids, unlike neurokinins (Mantyh et al., 1995; Abbadie et al., 1997; Allen et al., 1997; Marvizon et al., 1997, 1999a; Trafton et al., 2001), do not normally operate by "volume transmission," (i.e., by activating extrasynaptic receptors over a large region) (Fuxe and Agnati, 1991). Although released opioids inhibited dorsal horn neurons by activating MOR (Budai and Fields, 1998), this may be because of the activation of synaptic MOR. Indeed, we found opioid-containing terminals in close proximity to MOR-expressing dorsal horn neurons. Whether synaptic and extrasynaptic MORs are differently associated with peptidases needs to be investigated.

Yet, it is unlikely that the abundant extrasynaptic MOR-1 in dorsal horn neurons serves no function; hence, there may be some conditions in which opioids act by volume transmission. First, during inflammation and hyperalgesia, dynorphin and enkephalins are upregulated (Draisci et al., 1991; MacArthur et al., 1999; Wang et al., 2000). However, although the spinal release of 
dynorphin was increased during inflammation, Met-enkephalin release was reduced (Pohl et al., 1997), and noxious stimulation during inflammation failed to produce MOR-1 internalization (Trafton et al., 2000). Second, peptidase activity could be downregulated in some conditions. For example, the activity of a substance $\mathrm{P}$ endopeptidase in the spinal cord was altered during morphine tolerance and withdrawal (Zhou et al., 2001). Moreover, an enkephalin-degrading aminopeptidase can be switched between cytosolic and membrane-bound forms (Dyer et al., 1990). Third, these peptidases also degrade other neuropeptides, notably neurokinins (Duggan et al., 1992), and could become saturated when neuropeptides are released in large amounts or inhibited otherwise. For example, enkephalin-degrading aminopeptidases are inhibited by substance P (Hersh, 1985; Shimamura et al., 1991).

\section{Therapeutic implications}

It has been suggested that peptidase inhibitors could be used to treat pain, because they have analgesic effects (Noble et al., 1992a) and do not produce tolerance and addiction (Noble et al., 1992b,c; Whistler et al., 1999; Roques, 2000). This may be because pain causes the release of opioids in the dorsal horn but not in brain areas involved in addiction. Although these peptidases also degrade neurokinins (Duggan et al., 1992), peptidase inhibitors had a comparatively small effect on their ability to produce neurokinin 1 receptor internalization in dorsal horn neurons (X. Wang and J. C. G. Marvizón, unpublished observations). Our findings underscore the importance of inhibiting dipeptidyl carboxypeptidase, in addition to aminopeptidase $\mathrm{N}$ and neutral endopeptidase (Noble et al., 1992a,b; Roques, 2000), to fully protect the analgesic effect of endogenously released opioids.

\section{References}

Abbadie C, Trafton J, Liu H, Mantyh PW, Basbaum AI (1997) Inflammation increases the distribution of dorsal horn neurons that internalize the neurokinin-1 receptor in response to noxious and non-noxious stimulation. J Neurosci 17:8049-8060.

Abbadie C, Pasternak GW, Aicher SA (2001) Presynaptic localization of the carboxy-terminus epitopes of the $\mu$ opioid receptor splice variants MOR-1C and MOR-1D in the superficial laminae of the rat spinal cord. Neuroscience 106:833-842.

Aimone LD, Yaksh TL (1989) Opioid modulation of capsaicin-evoked release of substance $P$ from rat spinal cord in vivo. Peptides 10:1127-1131.

Allen BJ, Rogers SD, Ghilardi JR, Menning PM, Kuskowski MA, Basbaum AI, Simone DA, Mantyh PW (1997) Noxious cutaneous thermal stimuli induce a graded release of endogenous substance $\mathrm{P}$ in the spinal cord: imaging peptide action in vivo. J Neurosci 17:5921-5927.

Allen BJ, Li J, Menning PM, Rogers SD, Ghilardi J, Mantyh PW, Simone DA (1999) Primary afferent fibers that contribute to increased substance P receptor internalization in the spinal cord after injury. J Neurophysiol 81:1379-1390.

Aoki K, Kajiwara M, Oka T (1984) The role of bestatin-sensitive aminopeptidase, angiotensin converting enzyme and thiorphan-sensitive "enkephalinase" in the potency of enkephalins in the guinea-pig ileum. Jpn J Pharmacol 36:59-65.

Arvidsson U, Riedl M, Chakrabarti S, Lee JH, Nakano AH, Dado RJ, Loh HH, Law PY, Wessendorf MW, Elde R (1995) Distribution and targeting of a $\mu$-opioid receptor MOR1 in brain and spinal cord. J Neurosci 15:3328-3341.

Basbaum AI, Fields HL (1984) Endogenous pain control systems: brainstem spinal pathways and endorphin circuitry. Annu Rev Neurosci 7:309-338.

Bell KM, Traynor JR (1998) Dynorphin A 1-8: stability and implications for in vitro opioid activity. Can J Physiol Pharmacol 76:325-333.

Bewley TA, Li CH (1985) Tertiary structure in deletion analogues of human $\beta$-endorphin: resistance to leucine aminopeptidase action. Biochemistry 24:6568-6571.

Bourgoin S, Le Bars D, Clot AM, Hamon M, Cesselin F (1990) Subcutane- ous formalin induces a segmental release of Met-enkephalin-like material from the rat spinal cord. Pain 41:323-329.

Budai D, Fields HL (1998) Endogenous opioid peptides acting at $\mu$-opioid receptors in the dorsal horn contribute to midbrain modulation of spinal nociceptive neurons. J Neurophysiol 79:677-687.

Burbach JP, De Kloet ER (1982) Proteolysis of $\beta$-endorphin in brain tissue. Peptides 3:451-453.

Cesselin F, Le Bars D, Bourgoin S, Artaud F, Gozlan H, Clot AM, Besson JM, Hamon M (1985) Spontaneous and evoked release of methionineenkephalin-like material from the rat spinal cord in vivo. Brain Res 339:305-313.

Cesselin F, Bourgoin S, Clot AM, Hamon M, Le Bars D (1989) Segmental release of met-enkephalin-like material from the spinal-cord of rats, elicited by noxious thermal stimuli. Brain Res 484:71-77.

Chou J, Tang J, Del Rio J, Yang HY, Costa E (1984) Action of peptidase inhibitors on methionine5-enkephalin-arginine6-phenylalanine7 (YGGFMRF) and methionine5-enkephalin (YGGFM) metabolism and on electroacupuncture antinociception. J Pharmacol Exp Ther 230:349-352.

Dickenson AH, Sullivan AF, Fournie-Zaluski MC, Roques BP (1987) Prevention of degradation of endogenous enkephalins produces inhibition of nociceptive neurones in rat spinal cord. Brain Res 408:185-191.

Draisci G, Kajander KC, Dubner R, Bennett GJ, Iadarola MJ (1991) Upregulation of opioid gene expression in spinal cord evoked by experimental nerve injuries and inflammation. Brain Res 560:186-192.

Duggan AW, Schaible H-G, Hope PJ, Lang CW (1992) Effect of peptidase inhibition on the pattern of intraspinally released immunoreactive substance $\mathrm{P}$ detected with antibody microprobes. Brain Res 579:261-269.

Dyer SH, Slaughter CA, Orth K, Moomaw CR, Hersh LB (1990) Comparison of the soluble and membrane-bound forms of the puromycinsensitive enkephalin-degrading aminopeptidases from rat. J Neurochem 54:547-554.

Eckersell CB, Popper P, Micevych PE (1998) Estrogen-induced alteration of $\mu$-opioid receptor immunoreactivity in the medial preoptic nucleus and medial amygdala. J Neurosci 18:3967-3976.

Fields HL, Heinricher MM, Mason P (1991) Neurotransmitters in nociceptive modulatory circuits. Annu Rev Neurosci 14:219-245.

Fuxe K, Agnati LF (1991) Two principal modes of electrochemical communication in the brain: volume versus wiring transmission. In: Volume transmission in the brain (Fuxe K, Agnati LF, eds), pp 1-9. New York: Raven.

Graf L, Paldi A, Patthy A (1985) Action of neutral metalloendopeptidase ("enkephalinase") on $\beta$-endorphin. Neuropeptides 6:13-19.

Gramsch C, Meo T, Riethmuller G, Herz A (1983) Binding characteristics of a monoclonal $\beta$-endorphin antibody recognizing the $\mathrm{N}$-terminus of opioid peptides. J Neurochem 40:1220-1226.

Guyon A, Roques BP, Guyon F, Foucault A, Perdrisot R, Swerts JP, Schwartz JC (1979) Enkephalin degradation in mouse brain studied by a new H. P. L. C. method: further evidence for the involvement of carboxydipeptidase. Life Sci 25:1605-1611.

Hersh LB (1985) Characterization of membrane-bound aminopeptidases from rat brain: identification of the enkephalin-degrading aminopeptidase. J Neurochem 44:1427-1435.

Hersh LB, Aboukhair N, Watson S (1987) Immunohistochemical localization of aminopeptidase $\mathrm{M}$ in rat brain and periphery: relationship of enzyme localization and enkephalin metabolism. Peptides 8:523-532.

Hiranuma T, Oka T (1986) Effects of peptidase inhibitors on the [Met5]enkephalin hydrolysis in ileal and striatal preparations of guinea-pig: almost complete protection of degradation by the combination of amastatin, captopril and thiorphan. Jpn J Pharmacol 41:437-446.

Hiranuma T, Iwao K, Kitamura K, Matsumiya T, Oka T (1997) Almost complete protection from [Met5]-enkephalin-Arg6-Gly7-Leu8 (Metenk-RGL) hydrolysis in membrane preparations by the combination of amastatin, captopril and phosphoramidon. J Pharmacol Exp Ther 281:769-774.

Hiranuma T, Kitamura K, Taniguchi T, Kobayashi T, Tamaki R, Kanai M, Akahori K, Iwao K, Oka T (1998a) Effects of three peptidase inhibitors, amastatin, captopril and phosphoramidon, on the hydrolysis of [Met5]enkephalin-Arg6-Phe7 and other opioid peptides. Naunyn Schmiedebergs Arch Pharmacol 357:276-282.

Hiranuma T, Kitamura K, Taniguchi T, Kanai M, Arai Y, Iwao K, Oka T (1998b) Protection against dynorphin-(1-8) hydrolysis in membrane 
preparations by the combination of amastatin, captopril and phosphoramidon. J Pharmacol Exp Ther 286:863-869.

Honore P, Menning PM, Rogers SD, Nichols ML, Basbaum AI, Besson JM, Mantyh PW (1999) Spinal cord substance P receptor expression and internalization in acute, short-term, and long-term inflammatory pain states. J Neurosci 19:7670-7678.

Hui KS, Gioannini T, Hui M, Simon EJ, Lajtha A (1985) An opiate receptorassociated aminopeptidase that degrades enkephalins. Neurochem Res 10:1047-1058.

Hui KS, Saito M, Hui M (1998) A novel neuron-specific aminopeptidase in rat brain synaptosomes. Its identification, purification, and characterization. J Biol Chem 273:31053-31060.

Keith DE, Anton B, Murray SR, Zaki PA, Chu PC, Lissin DV, MonteilletAgius G, Stewart PL, Evans CJ, von Zastrow M (1998) $\mu$-Opioid receptor internalization: opiate drugs have differential effects on a conserved endocytic mechanism in vitro and in the mammalian brain. Mol Pharmacol 53:377-384.

Kemp T, Spike RC, Watt C, Todd AJ (1996) The $\mu$-opioid receptor (MOR1) is mainly restricted to neurons that do not contain GABA or glycine in the superficial dorsal horn of the rat spinal cord. Neuroscience 75:1231-1238.

Kishioka S, Miyamoto Y, Fukunaga Y, Nishida S, Yamamoto H (1994) Effects of a mixture of peptidase inhibitors (amastatin, captopril and phosphoramidon) on Met-enkephalin-, $\beta$-endorphin-, dynorphin-(1-13)-, and electroacupuncture-induced antinociception in rats. Jpn J Pharmacol 66:337-345.

Kitamura K, Akahori K, Yano H, Iwao K, Oka T (2000) Effects of peptidase inhibitors on anti-nociceptive action of dynorphin-(1-8) in rats. Naunyn Schmiedebergs Arch Pharmacol 361:273-278.

Law PY, Wong YH, Loh HH (2000) Molecular mechanisms and regulation of opioid receptor signaling. Annu Rev Pharmacol Toxicol 40:389-430.

Le Bars D, Bourgoin S, Clot AM, Hamon M, Cesselin F (1987a) Noxious mechanical stimuli increase the release of Met-enkephalin-like material heterosegmentally in the rat spinal cord. Brain Res 402:188-192.

Le Bars D, Bourgoin S, Villanueva L, Clot AM, Hamon M, Cesselin F (1987b) Involvement of the dorsolateral funiculi in the spinal release of metenkephalin-like material triggered by heterosegmental noxious mechanical stimuli. Brain Res 412:190-195.

Li J, WilkE, Wilk S (1995) Aminoacylpyrrolidine-2-nitriles: potent and stable inhibitors of dipeptidyl-peptidase IV (CD 26). Arch Biochem Biophys 323:148-154.

Liu H, Mantyh PW, Basbaum AI (1997) NMDA-receptor regulation of substance P release from primary afferent nociceptors. Nature 386:721-724.

Lucas D, Yaksh TL (1990) Release in vivo of Met-enkephalin and encrypted forms of Met-enkephalin from brain and spinal cord of the anesthetized cat. Peptides 11:1119-1125.

MacArthur L, Ren K, Pfaffenroth E, Franklin E, Ruda MA (1999) Descending modulation of opioid-containing nociceptive neurons in rats with peripheral inflammation and hyperalgesia. Neuroscience 88:499-506.

Mansour A, Khachaturian H, Lewis ME, Akil H, Watson SJ (1988) Anatomy of CNS opioid receptors. Trends Neurosci 11:308-314.

Mantyh PW, DeMaster E, Malhotra A, Ghilardi JR, Rogers SD, Mantyh CR, Liu H, Basbaum AI, Vigna SR, Maggio JE (1995) Receptor endocytosis and dendrite reshaping in spinal neurons after somatosensory stimulation. Science 268:1629-1632.

Marvizon JCG, Song B (2002) Opioids are not co-released with neurokinins from primary afferent terminals in the rat dorsal horn. Soc Neurosci Abstr 28:259.4.

Marvizon JC, Martinez V, Grady EF, Bunnett NW, Mayer EA (1997) Neurokinin 1 receptor internalization in spinal cord slices induced by dorsal root stimulation is mediated by NMDA receptors. J Neurosci 17:8129-8136

Marvizon JC, Grady EF, Stefani E, Bunnett NW, Mayer EA (1999a) Substance $\mathrm{P}$ release in the dorsal horn assessed by receptor internalization: NMDA receptors counteract a tonic inhibition by GABA(B) receptors. Eur J Neurosci 11:417-426.

Marvizon JCG, Grady EF, Wazsak-McGee J, Mayer EA (1999b) Internalization of $\mu$-opioid receptors in rat spinal cord slices. NeuroReport 10:2329-2334.

Noble F, Soleilhac JM, Soroca-Lucas E, Turcaud S, Fournie-Zaluski MC, Roques BP (1992a) Inhibition of the enkephalin-metabolizing enzymes by the first systemically active mixed inhibitor prodrug RB 101 induces potent analgesic responses in mice and rats. J Pharmacol Exp Ther 261:181-190.

Noble F, Turcaud S, Fournie-Zaluski MC, Roques BP (1992b) Repeated systemic administration of the mixed inhibitor of enkephalin-degrading enzymes, RB101, does not induce either antinociceptive tolerance or cross-tolerance with morphine. Eur J Pharmacol 223:83-89.

Noble F, Coric P, Fournie-Zaluski MC, Roques BP (1992c) Lack of physical dependence in mice after repeated systemic administration of the mixed inhibitor prodrug of enkephalin-degrading enzymes, RB101. Eur J Pharmacol 223:91-96.

Noble F, Banisadr G, Jardinaud F, Popovici T, Lai-Kuen R, Chen H, Bischoff L, Parsadaniantz SM, Fournie-Zaluski MC, Roques BP (2001) First discrete autoradiographic distribution of aminopeptidase $\mathrm{N}$ in various structures of rat brain and spinal cord using the selective iodinated inhibitor $\left[{ }^{125} \mathrm{I}\right] \mathrm{RB}$ 129. Neuroscience 105:479-488.

Numata H, Hiranuma T, Oka T (1988) Inactivation of dynorphin-(1-8) in isolated preparations by three peptidases. Jpn J Pharmacol 47:417-423.

Oka T, Aoki K, Kajiwara M, Ishii K, Kuno Y, Hiranuma T, Matsumiya T (1986) Inactivation of [Leu5]-enkephalin in three isolated preparations: relative importance of aminopeptidase, endopeptidase-24.11 and peptidyl dipeptidase A. NIDA Res Monogr 75:259-262.

Ozaki M, Miyamoto Y, Kishioka S, Masuda Y, Yamamoto H (1994) Effect of some peptidase inhibitors on exogenous and endogenous opioid actions in guinea-pig ileum. Biol Pharm Bull 17:62-69.

Pierce TL, Grahek MD, Wessendorf MW (1998) Immunoreactivity for endomorphin-2 occurs in primary afferents in rats and monkey. NeuroReport 9:385-389.

Pohl M, Ballet S, Collin E, Mauborgne A, Bourgoin S, Benoliel JJ, Hamon M, Cesselin F (1997) Enkephalinergic and dynorphinergic neurons in the spinal cord and dorsal root ganglia of the polyarthritic rat: in vivo release and cDNA hybridization studies. Brain Res 749:18-28.

Przewlocka B, Lason W, Dziedzicka M (1990) Modulation of prodynorphin peptides release from the rat spinal cord in vitro. Neuropeptides 16:201-206.

Przewlocki R, Przewlocka B (2001) Opioids in chronic pain. Eur J Pharmacol 429:79-91.

Randic M, Jiang MC, Cerne R (1993) Long-term potentiation and longterm depression of primary afferent neurotransmission in the rat spinal cord. J Neurosci 13:5228-5241.

Raynor K, Kong H, Chen Y, Yasuda K, Yu L, Bell GI, Reisine T (1993) Pharmacological characterization of the cloned $\kappa^{-}, \delta$-, and $\mu$-opioid receptors. Mol Pharmacol 45:330-334.

Roques BP (2000) Novel approaches to targeting neuropeptide systems. Trends Pharmacol Sci 21:475-483.

Sandkuhler J, Chen JG, Cheng G, Randic M (1997) Low-frequency stimulation of afferent $\mathrm{A} \delta$-fibers induces long-term depression at primary afferent synapses with substantia gelatinosa neurons in the rat. J Neurosci 17:6483-6491.

Satoh E, Nakazato Y (1991) Effects of monensin and veratridine on acetylcholine release and cytosolic free $\mathrm{Ca}^{2+}$ levels in cerebrocortical synaptosomes of rats. J Neurochem 57:1270-1275.

Shane R, Wilk S, Bodnar RJ (1999) Modulation of endomorphin-2-induced analgesia by dipeptidyl peptidase IV. Brain Res 815:278-286.

Shimamura M, Hazato T, Katayama T (1983) A membrane-bound aminopeptidase isolated from monkey brain and its action on enkephalin. Biochim Biophys Acta 756:223-229.

Shimamura M, Hazato T, Iwaguchi T (1991) Enkephalin-degrading aminopeptidase in the longitudinal muscle layer of guinea pig small intestine: its properties and action on neuropeptides. J Biochem (Tokyo) 109:492-497.

Song B, Marvizon JCG (2002) Peptidases restrict $\mu$-opioid receptor activation by enkephalins but not endomorphins in the rat dorsal horn. Soc Neurosci Abstr 28:654.1.

Spike RC, Puskar Z, Sakamoto H, Stewart W, Watt C, Todd AJ (2002) MOR-1-immunoreactive neurons in the dorsal horn of the rat spinal cord: evidence for nonsynaptic innervation by substance P-containing primary afferents and for selective activation by noxious thermal stimuli. Eur J Neurosci 15:1306-1316.

Suzuki H, Yanagisawa M, Yoshioka K, Hosoki R, Otsuka M (1997) Enzymatic inactivation of enkephalin neurotransmitters in the spinal cord of the neonatal rat. Neurosci Res 28:261-267.

Tieku S, Hooper NM (1992) Inhibition of aminopeptidases N, A and W. A 
re-evaluation of the actions of bestatin and inhibitors of angiotensin converting enzyme. Biochem Pharmacol 44:1725-1730.

Todd AJ, Spike RC (1993) The localization of classical transmitters and neuropeptides within neurons in laminae I-III of the mammalian spinal dorsal horn. Prog Neurobiol 41:609-645.

Tomboly C, Peter A, Toth G (2002) In vitro quantitative study of the degradation of endomorphins. Peptides 23:1573.

Trafton J, Abbadie C, Liu H, Basbaum AI (1997) Internalization of the $\mu$ opioid receptor (MOR) in spinal cord neurons of the rat in vivo. Soc Neurosci Abstr 23:175.16.

Trafton JA, Abbadie C, Marchand S, Mantyh PW, Basbaum AI (1999) Spinal opioid analgesia: how critical is the regulation of substance P signaling? J Neurosci 19:9642-9653.

Trafton JA, Abbadie C, Marek K, Basbaum AI (2000) Postsynaptic signaling via the $\mu$-opioid receptor: responses of dorsal horn neurons to exogenous opioids and noxious stimulation. J Neurosci 20:8578-8584.

Trafton JA, Abbadie C, Basbaum AI (2001) Differential contribution of substance $\mathrm{P}$ and neurokinin A to spinal cord neurokinin-1 receptor signaling in the rat. J Neurosci 21:3656-3664.

Tseng LF, King RC, Fujimoto JM (1986) Lack of inhibitory effect of aprotinin and bacitracin on the spinal release of Met-enkephalin induced by intraventricular $\beta$-endorphin. Peptides 7:369-371.

Uzumaki U, Govoni S, Faccini E, Pasinetti G, Missale C, Trabucchi M (1984) Neuropeptidergic inhibitory regulation of Met-enkephalin immunoreactive material release from rat spinal cord in vitro. Peptides 5:849-852.
Wang H, Wang R, Nie H, Zhang R, Qiao JT (2000) Neurokinin A, calcitonin gene-related peptide, and dynorphin A (1-8) in spinal dorsal horn contribute to descending inhibition evoked by nociceptive afferent pathways: an immunocytochemical study. Regul Pept 89:7-12.

Whistler JL, Chuang HH, Chu P, Jan LY, von Zastrow M (1999) Functional dissociation of $\mu$ opioid receptor signaling and endocytosis: implications for the biology of opiate tolerance and addiction. Neuron 23:737-746.

Williams JT, Christie MJ, North RA, Roques BP (1987) Potentiation of enkephalin action by peptidase inhibitors in rat locus ceruleus in vitro. J Pharmacol Exp Ther 243:397-401.

Yaksh TL, Chipkin RE (1989) Studies on the effect of SCH-34826 and thiorphan on [Met5] enkephalin levels and release in rat spinal cord. Eur J Pharmacol 167:367-373.

Yaksh TL, Elde RP (1981) Factors governing release of methionine enkephalin-like immunoreactivity from mesencephalon and spinal cord of the cat in vivo. J Neurophysiol 46:1056-1075

Yaksh TL, Jessell TM, Gamse R, Mudge AW, Leeman SE (1980) Intrathecal morphine inhibits substance $\mathrm{P}$ release from mammalian spinal cord in vivo. Nature 286:155-157.

Zadina JE, Hackler L, Ge L-J, Kastin AJ (1997) A potent and selective endogenous agonist for the $\mu$-opiate receptor. Nature 386:499-502.

Zhou Q, Karlsson K, Liu Z, Johansson P, Le Greves M, Kiuru A, Nyberg F (2001) Substance P endopeptidase-like activity is altered in various regions of the rat central nervous system during morphine tolerance and withdrawal. Neuropharmacology 41:246-253. 